\title{
O FÍGADO NAS LEPTOSPIROSES *
}

\author{
Adrelirio José Rios Gonçalves ** Danilo Oliveira Lins *** Lucia Emi Suzuki **** \\ Francisco Duarte $* * * * *$ Marialva Ferreira $* * * * * *$ Jarbas Andrade $* * * * * *$
}

\begin{abstract}
Os autores chamam a atenção para o aspecto endêmico-epidêmico da injecção na Guanabara e regióes próximas.

Assinalam fatos referentes a gravidade da infecção $e$ ao pouco conhecimento das formas anictéricas.

Dão ênfase às manifestações aigestivas e assinalam $\Omega$ importancia de se incluir as leptospiroses no diagnostico diferencial de abdome cirurgico principalmente aqueles com ictericia. Consideram como sinais de prognóstico grave a insuficiência renal aguda com anüria, e presença de hemorragia digestiva, convulsōes e/ou choque.

Das exteriorizaçôes aigestivas o comprometimento hepático e a ictericia são os itens analisados no trabalho.

O material estudado consta de 42 casos analisados do ponto de vista funcional e histopatológico sendo que o material de autopsia foi obtido ae apenas 3 casos $e$ o restante, através de punçäo-biopsia.

O maior grau de ictericia foi alcancado na $2^{\mathbf{a}}$ e $3^{\mathrm{a}}$ semanas de doença e o predominio absoluto é o da fração da bilirrubina direta.

Elevaçōes expressivas da fosfatase alcalina e colesterol ao lado de hiperbilirrubinemias severas em tôrno da 2a e $3^{\mathrm{a}}$ semana de aença, configuraram em muitos casos um componente obstrutivo importante com correspondencia nos achados de histopatologia. Em nenhuma ocasiâo as transaminases ultrapassaram a 250 u Karmen assim como necrose hepática em nenhum espécime histopatológico foi importante.

22 pacientes apresentaram citras de atividade protrombinica interiores a $60 \%$ os casos aue receberam vitamina $K 1$, respostas não foram obtidas.

Os principais elementos de eletroforese protéica encontrados em 26 pacientes foram: hipoalbuminemia em todos, alfa 2 elevada sem exceção, beta acima de $0,90 \mathrm{~g} \% \mathrm{em} 14 \mathrm{e}$ gama superior a 1,4 em 15

As provas de floculação e turvaçāo se mostraram bastante alteradas em 14

Os principais elementos de patologia encontrados foram localização centrolobular da lesāo, dissociação trabecular, colestase, degeneração e regeneração hepatocitárias e proliferaçāo kupfferiana. Estas lesóes podem ser encontradas em pacientes com história clínica de mais de 30 dias de evolucão.

Fina izam discutindo a patogenia da doença e a fisiopatologia das alteraçóes llepáticas no decurso das leptospiroses.
\end{abstract}

As leptospiroses são atualmente um sério e grave problema de Saúde Pública no Estado da Guanabara e regiões próximas. E freqüente entre nós porém uma extensão aproximada de seu papel endêmico ou $\mathrm{cpi-}$ dêmico ainđa não está delienada.

Os Quadros I e II dão-nos uma idéia do número de pacientes internados no Hospi- tal Estadual Francisco de Castro nos anos de 1967 e 1969. É de se ressaltar o aspecto endêmico da doença com surtos epidêmi$\cos$ nos meses de fevereiro, março e abril que coincidem com épocas de chuvas com alagamentos e maior exposição da população aos meios de contágio. Nos períodos analisados não foram incluídas formas

* Trabalho realizado pelos Serviços de Clinica Médica do Hospital Estadual Francisco de Castro e do Hospital dos Servidores do Estado e pelo Servico de Anatomla Patológica do H. S. E.

* Médico do Serviço de Clínica Médica do H. S. E. e do Hospital Estadual Francisco de Castro, Rlo. Guanabara.

** Médico do Setor de Gastroenterologia do Serviço de Clínica Médica do $H . S . \mathbf{E}$.

$\star \star \star \star$ Médico-Residente do Serviço de Clínica Médica do H. $\mathbf{S}$. $\mathbf{E}$.

$\star \star \star \star *$ Chefe de Clínica do Serviço de Anatomia Patológica do H. S. E.

$\star * \star * * *$ Médico-Residente do Servtço de Anatomia Patológica do H. S. E.

****** Chefe da Seção de Leptosptras na Escola de Saúde Pública da Gb (Mangulnhos). Auxillar de Ensino na Escola de Saúde Pública.

Recebido para publicação em 24-12-1870. 
anictéricas desde que nenhum caso foi hospitalizado.

Em 1968 o problema foi bastante semelhante porém 3 formas anictéricas foram diagnosticadas. No presente ano, até a época de realização do estudo, 4 formas anictéricas foram confirmadas e fazem parte do trabalho.

Fato importante a ser comentado é a alta mortalidade da infecção, cuja situação continua inalterada.

De outubro de 1969 a março de 1970, época do material incluído para estudo do Hospital Francisco de Castro, 41 casos foram registrados dos quais 11 tiveram evolução fatal.

O reconhecimento da infecção entre nós é quase que exclusivo das formas ictéricas ou das que configuram o sindrome de Weil, êste último em realidade constitui uma minoria dos casos que compõem o amplo espectro clinico das infecções por leptospiras, sendo no entanto tal síndrome bastante presenciado por nós.

A realidade do problema é que em geral sòmente estas formas clínicas são internadas, as formas anictéricas ficam sem diagnóstico mesmo quando hospitalizadas, são tratadas como estades gripais, rotuladas como viroses, febre tifóide ou meningites a líquor claro, permanecendo sem reconhecimento clínico (1) .

Assinalamos ainda que uma grande parte das formas ictéricas recebe o rótulo de hepatite infecciosa e dados epidemiológicos, clínicos, bioquímicos e de exames complementares não são corretamente investigados ou interpretados fazendo com que passem também sem reconhecimento. ESTADUAL FRANCISCO DE CASTRO - ANO DE 1967

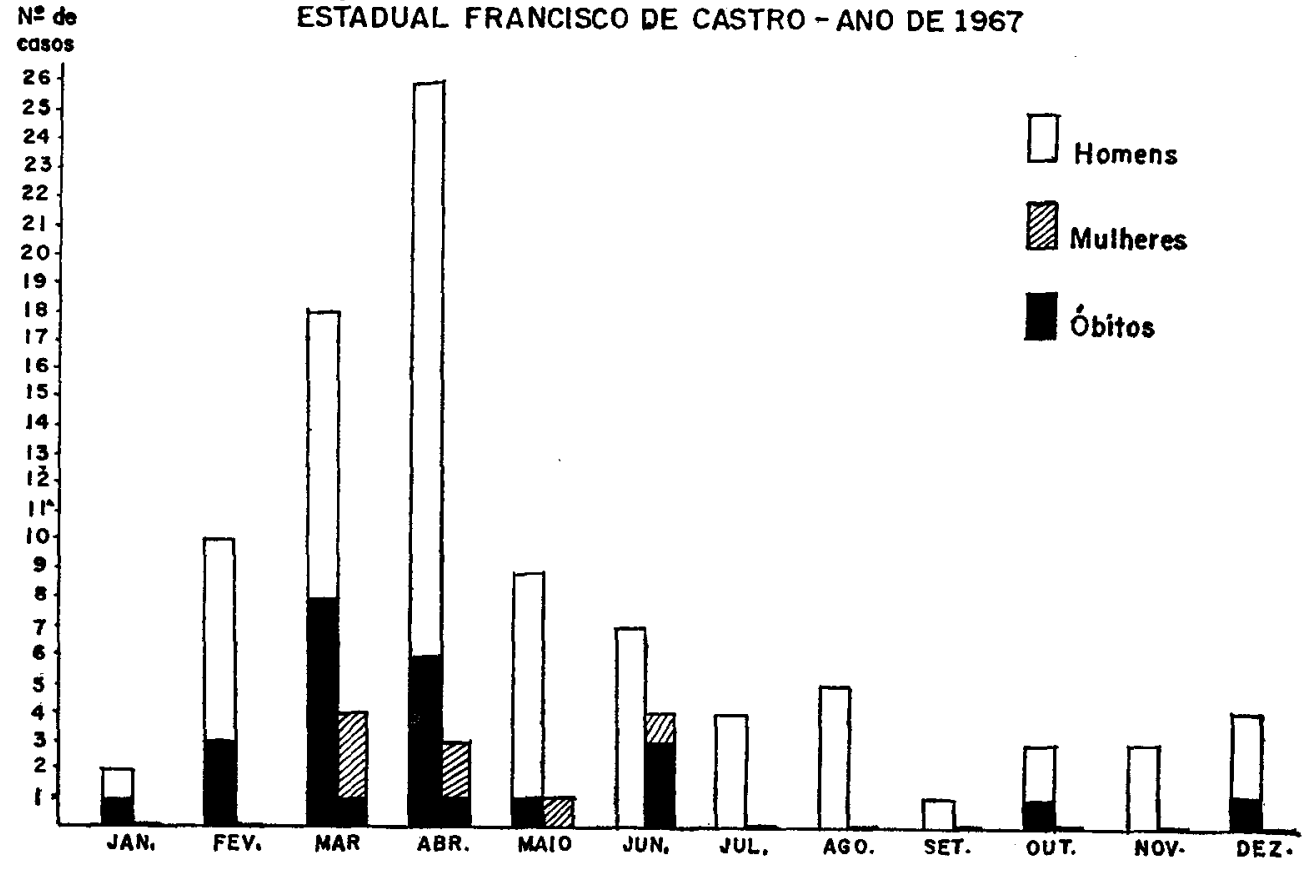

Total - 104 cosos - Homens -92

Mulheres -12

óbitos- 26

Criança - 0 
A nossa experiência prende-se quase que tctalmente as formas ictéricas da doença e aos quadros mais graves com manifestaçōes hemorrágicas, lesão renal, torpor, coma, rigidez de nuca, convulsões, hipotensão arterial, desidratação severa, geralmente precedidos por febre elevada, calefrios, mialgias, impossibilidade de deambular, cefaléia, náuseas, vômitos, distúrbios psíquicos, dor abdominal, etc.

As manifestações digestivas são muito freqüentes em tôdas as formas clínicas de leptospirose, e raramente estão ausentes, fato assinalado na literatura e presente em todo o nosso material $(1,26,29,32,34)$. A análise do Quadro III destaca bem o que acabamos de afirmar. Destas as principais são as náuseas, os vômitos, dor abdominal, diarréia às vêzes intensa, em outras ocasiōes obtipação intestinal.

Importante fato assinalado na literatura $(1,17,19,26,29,33,34,39)$ e em várias ocasiōes por nós constatado, é a confusão entre leptospirose e quadros abdominais cirúrgicos, particularmente colecistite aguda ou icterícia obstrutiva por cálculos seguida de colangite. Tais erros de interpretação não são difíceis de serem cometidos, desde que febre, dor abdominal, náuseas, vômitos e ictericia às vêzes precoce, são freqüentemente os sintomas que abrem o quadro clínico de uma infecção por leptospira.

Pancreatite aguda é outra condição digestiva que tem sido assinalada como complicação de leptospirose, e verificada de forma expressiva do ponto de vista clínico e na autopsia em 1 dos casos do presente estudo (caso 5).

As dores abdominais no decurso das leptospiroses são às vêzes tão intensas que simulam um quadro de cólica biliar, de pancreatite aguda ou de perfuração de uma víscera oca. Estes fatos são aqui lembrados devido à alta incidência desta infecção

QUADRO II

DISTRIBUIÇÃO ANUAL DOS CASOS DE LEPTOSPIROSE NO HOSPITAL ESTADUAL FRANCISCO DE CASTRO-ANO DE 1969

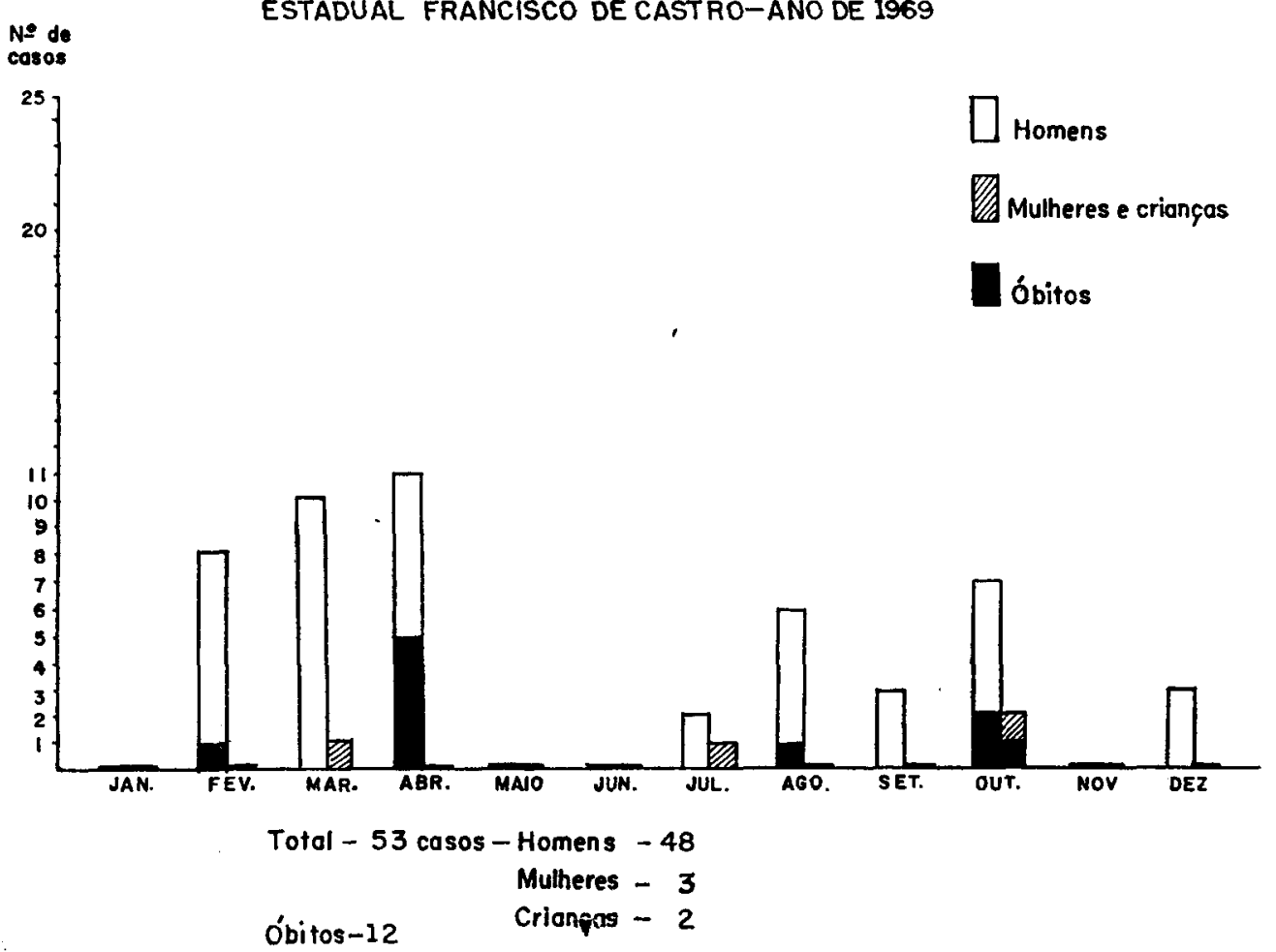




\section{QUADRO III}

Sinais e sintomas relativos ao aparelho digestivo em 42 casos de leptospirose.

Náuseas

Vômitos

Dor abdominal

Diarréia

Obstipação

Hepatomegalia

Icterícia

\begin{tabular}{c|c}
$\begin{array}{c}\text { No de } \\
\text { casos }\end{array}$ & $\begin{array}{c}\text { Percen- } \\
\text { tual }\end{array}$ \\
& \\
$23 / 42$ & 55 \\
$25 / 42$ & 59 \\
$30 / 42$ & 71 \\
$17 / 42$ & 40 \\
$9 / 42$ & 21 \\
$36 / 42$ & 86 \\
$38 / 42$ & 90
\end{tabular}

em nossa regiăo e em presença de ccndições abdominais cirúrgicas com ictericia, a leptospirose deve sempre ser considerada no diagnóstico diferencial e outras manifestações da doença devem ser procuradas. E óbvio que uma cirurgia abdominal numa condição em que alterações hemcrrágicas estão presentes pode trazer resultados desastrosos para os pacientes.

As hemorragias digestivas podem fazer parte dos distúrbios hemorrágicos e são de etiopatogenia ainda bastante desccnhecida e se expressam fundamentalmente por hematêmese, melena ou enterorragia, separadas ou imbricadas em um mesmo doente. Comprovando a afirmação de que as formas clínicas por nós observadas são geralmente severas, está o levantamento realizado em 150 pacientes do Hospital Estadual Francisco de Castro. Dêstes 150, 22 tiveram sangramento digestivo e neste grupo a mortalidade foi de $50 \%$ (Quadro IV).

\section{QUADRO IV}

Incidência de hemorragia digestiva em 150 casos de leptospirose

\begin{tabular}{l|c|c} 
& $\begin{array}{c}\text { No de } \\
\text { casos }\end{array}$ & Óbitos \\
Hematêmese & 10 & 6 \\
Melena & 6 & 3 \\
Enterorragia & 2 & 0 \\
Hematêmese e melena & 2 & 1 \\
Melena e enterorragia & 2 & 1 \\
\hline \multicolumn{1}{c}{ Total } & 22 & 11 \\
\hline
\end{tabular}

As hemorragias digestivas quando presentes são para nós um sinal de prognóstico bastante reservado, e em tais ocasióes são freqüentemente a causa imediata do óbito. Em nossa experiência a presença de insuficiência renal aguda com oligúria extrema ou anúria, hemorragia digestiva, convulsões ou choque, têm sido sinais de mau prognóstico, mesmo quando isoladas.

Do aparelho digestivo, o fígado é um importante alvo atingido nas infecções por êstes microorganismos.

Das exteriorizações clínicas de seu comprometimento, talvez seja a icterícia a mais importante por ser freqüente, por seu rápido reconhecimento ao exame clínico, por sua coloração cúprica ou rubínica, sinal físico impcrtante na suspeita diagnóstica etiológica. A hepatomegalia é outro importante elemento do exame físico e ocorreu em 36 casos dos 42 do estudo. É difícil a análise de algumas de suas características semióticas em conseqüência do ccmprometimento muscular abdominal nestas infecções.

A presença de icterícia entre nós em paciente mesmo sem referir uma história epidemiológica convincente, mas informando inicio súbito da doença com febre, calefrios, cefaléia, mialgias, náuseas, vômitos e dor abdominal, ccm ou sem fenômenos hemorrágicos e com ou sem sinais de comprometimento renal, é um elemento importante e altamente sugestivo de que o caso trata-se de leptospirose.

A intensidade da icterícia no decurso destas infecções é às vêzes assustadora $e$ têm sido os índices mais elevados de bilirrubinas por nós documentados, ultrapassando a todos os outros tipos de hepatopatias, pelo mencs em nossa experiência. Para se ter uma idéia da intensidade de tal manifestação clínica, apresentaremos um quadro no qual uma revisão de 128 casos de formas ictéricas da doença é feita, nāo incluídos no material que constitui o presente trabalho. Dêstes 128,37 apresentaram cifras supericres a $40 \mathrm{mg} \%$. Nesta série de 37,9 óbitos foram observados (Quadro $\mathrm{V})$.

Uma análise da icterícia e de outros distúrbios funcionais será realizada. As alterações histopatológicas encontradas em biopsias e necropsias serão descritas e uma correlação histofuncional será tentada. 


\section{QUADRD V}

Cifras máximas de bilirrubinemia em 128 pacientes com leptospirose: 37 casos acima de $40 \mathrm{mg} \%$

\begin{tabular}{|c|c|c|}
\hline $\begin{array}{c}\text { Bilirrubinemia } \\
(\mathrm{mg} \%)\end{array}$ & $\begin{array}{l}\text { No de } \\
\text { casos }\end{array}$ & óbitos \\
\hline $\begin{array}{l}40-49 \\
50-59 \\
60-69 \\
70-79 \\
80-89 \\
90\end{array}$ & $\begin{array}{r}14 \\
8 \\
7 \\
4 \\
3 \\
1\end{array}$ & $\begin{array}{l}1 \\
3 \\
0 \\
3 \\
1 \\
1\end{array}$ \\
\hline & 37 & 9 \\
\hline
\end{tabular}

Uma revisão da literatura será feita com a finalidade de esclarecimento a respeito dos mecanismos etiopatogênicos envolvidos na doença e na gênese da agressão hepática.

Conclusões deverão ser retiradas baseadas em ncssa própria experiência a respeito do assunto.

\section{MATERIAL}

O material apresentado consta de $42 \mathrm{ca}-$ sos 16 pacientes (casos 1 a 16) foram internados no Hospital dos Servidores do Estado no período entre maio de 1968 a março de 1970 e 26 (casos 17 a 42) no Hospital Estadual Francisco de Castro, selecionados entre outubro de 1969 a março de 1970; dêste período sòmente foram incluídcs os casos que tiveram estudo funcional hepático e biopsia ou dados de necropsia dêste órgão.

37 pacientes foram do sexo masculino, a idade mínima foi de 15 e a máxima de 63 ancs. Referências quanto a idade, sexo, côr e profissão são analisadas no Quadro VI. Todos os pacientes tiveram história clínica e exame físico compatíveis com leptospirose, 4 foram formas anictéricas da doença e tôdas elas $\mathrm{ccm}$ sôro-aglutinação positiva.

24 exibiram síndrome de Weil e 10 dêstes foram submetidos a diálise peritoneal por terem apresentado graves distúrbios metabólicos (hiperazotemia, hipercreatininemia, hiperpotassemia e baixa da reserva alcalina), 3 dêles faleceram.
Em 7 pacientes (casos 2, 4, 5, 7, 17, 20 e 21) a sôro-aglutinação não foi realizada, o diagnóstico foi essencialmente clínico auxiliado por exames laboratoriais e dados de histopatologia.

Em 4 a reação de sôro-aglutinação foi negativa (casos $12,15,18$ e 28 ), foram incluídos pcr se tratar de formas clínicas típicas da doença.

A sôro-aglutinação foi positiva em 31 pacientes e as técnicas utilizadas foram as com antígeno DIFCO (qualitativo e quantitativo) e a aglutinação ultra-microscópica com leptospiras vivas. O Quadro VII demonstra as principais espócies encontradas e os títulos de positividade respectivos.

\section{Método do estudo clínico}

Dos 42 pacientes, o estudo histopatológico do fígado foi obtido por punção-biopsio em 39. Em 3, os espécimes hepáticos incluidos no trabalho são de estudo de necropsia, realizadas com 11,14 e 15 dias de doença, respectivamente. O tempo mínimo de doença no qual a biopsia foi realizada foi de 13 dias e o máximo de 59. Das formas ictéricas sòmente 1 caso (.$^{\circ} 37$ ) apresentava nível de bilirrubina normal na época da biopsia. Os demais exibiam icterícia e o nível mínimo foi de 1,2 e o máximo de $11,2 \mathrm{mg} \%$ na época da biopsia. Os $3 \mathrm{ca}-$ sos com evolução fatal tinham nesta época $25,2,19,2$ e $30 \mathrm{mg} \%$. Tais detalhes poderão ser vistos no Quadro VIII. Nenhuma complicação foi observada nc que concerne a biopsia hepática.

Quanto ao estudo funcional nāo houve uniformidade com relação aos dois grupos de pacientes por pertencerem os mesmcs a instituições diferentes.

Na série do Hospital dos Servidores do Estado, o estudo compreendeu dosagens semanais de bilirrubinas, transaminases, fosfatase alcalina, colesterol, provas de turvação e flcculação, atividade protrombínica, proteinas totais e frações, eletroforese proteica; a prova da bromossulfaleina foi realizada em 4 casos e 1 paciente fêz a dosagem da desidrogenase lática (caso 15).

O grupo do Hospital Estadual Francisco de Castro não realizou acompanhamento semanal e o estudo constou de dosagens das transaminases, bilirrubinas, fosfatase alcalina, atividade protrombínica e provas 
QUADRO VI

C A S U I T I C A

\begin{tabular}{|c|c|c|c|c|c|}
\hline Caso & Registro & Icade & Sexo & Côr & Profissão \\
\hline $\begin{array}{r}1 \\
2 \\
3 \\
4 \\
5 \\
6 \\
7 \\
8 \\
9 \\
10 \\
11 \\
12 \\
13 \\
14 \\
15 \\
16 \\
17 \\
18 \\
19 \\
20 \\
21 \\
22 \\
23 \\
24 \\
25 \\
26 \\
27 \\
28 \\
29 \\
30 \\
31 \\
32 \\
33 \\
34 \\
35 \\
36 \\
37 \\
38 \\
39 \\
40 \\
41 \\
42\end{array}$ & $\begin{array}{r}295391 \\
282872 \\
67318 \\
396760 \\
355525 \\
33764 \\
136100 \\
73600 \\
401817 \\
101570 \\
163940 \\
399350 \\
264469 \\
412464 \\
216089 \\
315437 \\
15614 \\
15633 \\
16653 \\
15688 \\
15768 \\
15956 \\
16201 \\
16325 \\
16125 \\
16130 \\
16347 \\
16278 \\
16348 \\
16170 \\
16382 \\
16541 \\
16550 \\
16437 \\
16517 \\
16561 \\
16576 \\
16597 \\
16625 \\
16599 \\
16638 \\
16654\end{array}$ & $\begin{array}{l}44 \\
33 \\
56 \\
42 \\
45 \\
52 \\
35 \\
44 \\
33 \\
34 \\
15 \\
60 \\
30 \\
42 \\
37 \\
36 \\
35 \\
32 \\
24 \\
50 \\
33 \\
25 \\
16 \\
40 \\
56 \\
36 \\
24 \\
42 \\
45 \\
42 \\
63 \\
40 \\
30 \\
45 \\
15 \\
40 \\
39 \\
25 \\
38 \\
43 \\
25 \\
25\end{array}$ & 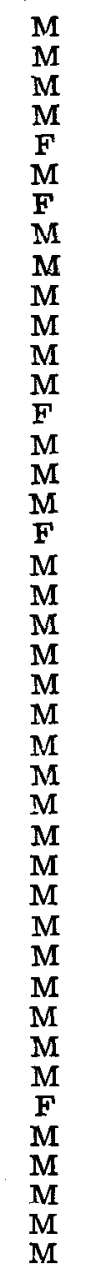 & $\begin{array}{c}\mathrm{Pd} \\
\mathrm{B} \\
\mathrm{Pt} \\
\mathrm{B} \\
\mathrm{B} \\
\mathrm{Pt} \\
\mathrm{Pd} \\
\mathrm{B} \\
\mathrm{Pd} \\
\mathrm{Pd} \\
\mathrm{Pd} \\
\mathrm{B} \\
\mathrm{B} \\
\mathrm{Pt} \\
\mathrm{Pd} \\
\mathrm{Pt} \\
\mathrm{Pt} \\
\mathrm{B} \\
\mathrm{Pd} \\
\mathrm{Pd} \\
\mathrm{B} \\
\mathrm{Pd} \\
\mathrm{Pd} \\
\mathrm{B} \\
\mathrm{B} \\
\mathrm{Pd} \\
\mathrm{Pd} \\
\mathrm{Pd} \\
\mathrm{Pd} \\
\mathrm{B} \\
\mathrm{Pd} \\
\mathrm{B} \\
\mathrm{Pd} \\
\mathrm{Pt} \\
\mathrm{B} \\
\mathrm{B} \\
\mathrm{Pd} \\
\mathrm{Pt} \\
\mathrm{Pt} \\
\mathrm{Pd} \\
\mathrm{Pd} \\
\mathrm{Pd}\end{array}$ & $\begin{array}{l}\text { Pintor } \\
\text { Funcionário público } \\
\text { Serviçal } \\
\text { Padejro } \\
\text { Doméstica } \\
\text { Artífice } \\
\text { Doméstica } \\
\text { Funcionário público } \\
\text { Servente } \\
\text { Carteiro } \\
\text { Aux. confeiteiro } \\
\text { Aposentado } \\
\text { Armazenista } \\
\text { Doméstica } \\
\text { Servente } \\
\text { Aux. portaria } \\
\text { Granjeiro } \\
\text { Doméstica } \\
\text { Biscateiro } \\
\text { Aposentado } \\
\text { Corretor } \\
\text { Vendedor } \\
\text { Estudante } \\
\text { Coveiro } \\
\text { Biscateiro } \\
\text { Pedreiro } \\
\text { Servente } \\
\text { Eletricista } \\
\text { Pedreiro } \\
\text { Biscateiro } \\
\text { Biscateiro } \\
\text { Industriário } \\
\text { Biscateiro } \\
\text { Biscateiro } \\
\text { Estudante } \\
\text { Lavrador } \\
\text { Doméstica } \\
\text { Biscateiro } \\
\text { Ajudante de caminhão } \\
\text { Servente de obras } \\
\text { Aux. dentista } \\
\text { Pintor }\end{array}$ \\
\hline
\end{tabular}




\section{Q U A D R O V I I}

Soro-aglutinação para leptospiras nos 42 casos

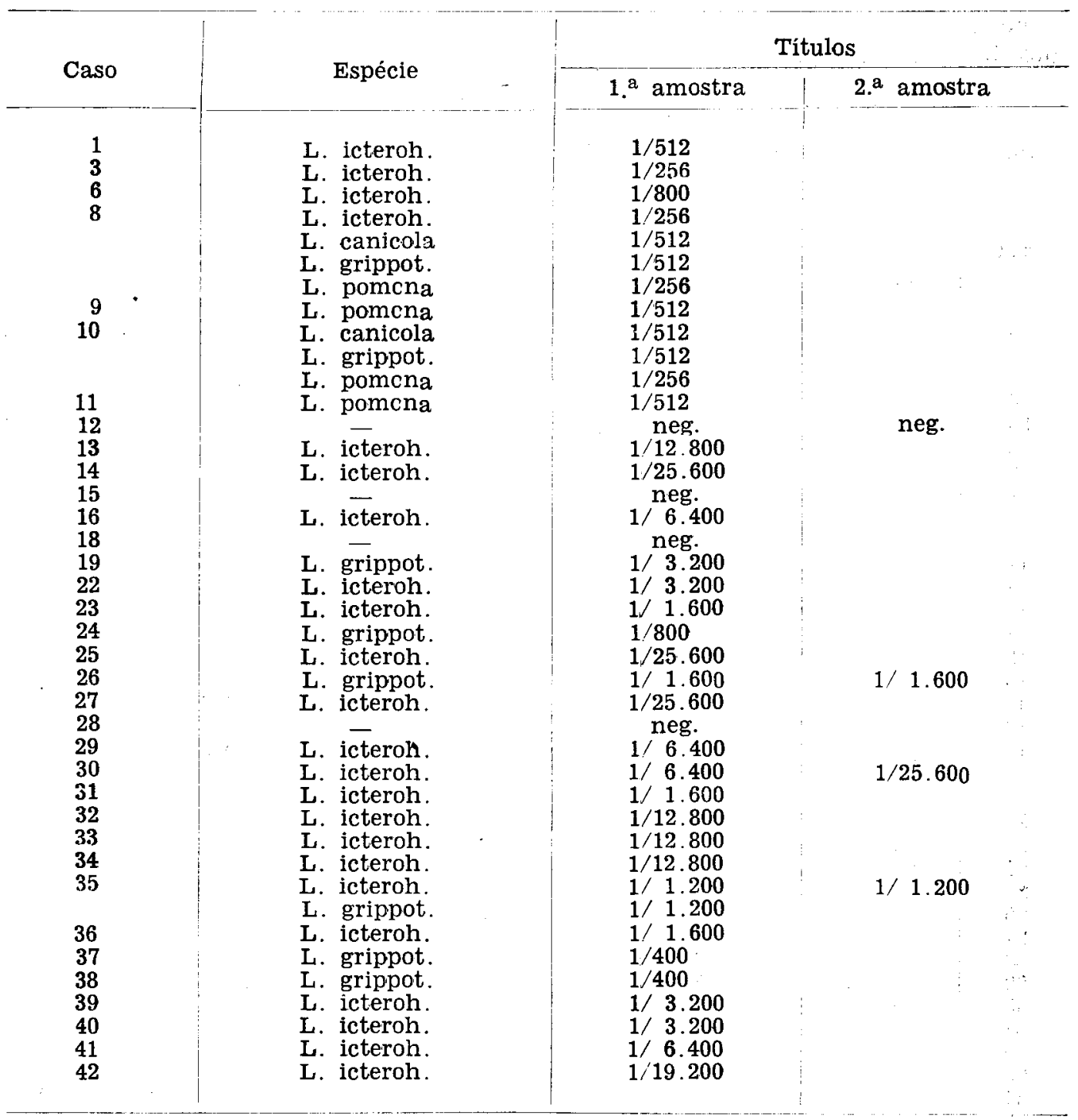

Nota - Nos casos 1, 3, 8, 9, 10 e 11 as técnicas utilizadas foram as com antigeno DIFCO (qualitativo e quantitativo) e nos demais casos, a aglutinação ultra-microscópica com leptospiras vivas. 
de turvação e floculação. Nos últimos pacientes dêste grupo o estudo foi mais completo e incluiu dosagens de colesterol, das proteinas totais e fraçóes e eletroforose proteica, em 1 caso a desidrogenase lática foi realizada (caso 33 ).

\section{Patologia - material e método}

Foram submetidos a estudo histopatológico, 42 espécimes hepáticcs, obtidos 39 por

\section{QUADRO VIII}

Estudo histcpatológico do fígado através de biopsia ou necropsia

\begin{tabular}{|c|c|c|}
\hline Caso & $\begin{array}{l}\text { N. de } \\
\text { dias de } \\
\text { doença }\end{array}$ & $\begin{array}{l}\text { Bilirrubinemia total } \\
\text { em mg\% na época do } \\
\text { estudo histopatológico }\end{array}$ \\
\hline $\begin{array}{r}1 \\
2 \\
3 \\
4 \\
5 \\
6 \\
7 \\
8 \\
9 \\
10 \\
11 \\
12 \\
13 \\
14 \\
15 \\
16 \\
17 \\
18 \\
19 \\
20 \\
21 \\
22 \\
23 \\
24 \\
25 \\
26 \\
27 \\
28 \\
29 \\
30 \\
31 \\
32 \\
33 \\
34 \\
35 \\
36 \\
37 \\
38 \\
39 \\
40 \\
41 \\
42\end{array}$ & $\begin{array}{l}15 \\
26 \\
22 \\
15 \\
14 \\
35 \\
30 \\
37 \\
59 \\
13 \\
17 \\
30 \\
26 \\
35 \\
14 \\
23 \\
27 \\
25 \\
26 \\
52 \\
35 \\
4.2 \\
26 \\
25 \\
29 \\
35 \\
18 \\
24 \\
29 \\
39 \\
38 \\
18 \\
22 \\
35 \\
16 \\
11 \\
33 \\
25 \\
24 \\
24 \\
17 \\
21\end{array}$ & $\begin{array}{c}25,2 \\
9 \\
7,8 \\
1,25 \\
1,92 \\
1,25 \\
\mathbf{2 , 5} \\
1,25 \\
1,55 \\
4,10 \\
4,10 \\
1,25 \\
11,2 \\
2,50 \\
4,35 \\
\mathbf{4 , 6 0} \\
1, \\
1,25 \\
5,0 \\
- \\
- \\
-7 \\
0,7 \\
1,7 \\
5,0 \\
4,2 \\
2,3 \\
2,0 \\
\mathbf{2 , 5} \\
1,8 \\
4,5 \\
\mathbf{5 , 4} \\
\mathbf{9 , 0} \\
\mathbf{5 , 0} \\
0,75 \\
30 \\
0,50 \\
0,75 \\
\mathbf{3 , 6 0} \\
0,75 \\
\mathbf{5 , 0} \\
1,2\end{array}$ \\
\hline
\end{tabular}

Nota - Cis casos 1,5 e 36 foram estudo de necropsia e cs demais através de punção-biopsia hepática. punção-biopsia e 3 por necropsia. Nesta mesma época foram realizadas dosagens da bilirrubinemia total e frações, fosfatase alcalina, colesterol, transaminases (TGO e TGP) ,atividade protrombínica, proteínas, eletroforese proteica e provas de turvação e floculação. O material hepático foi fixado em formol a $10 \%$ e submetido às seguintes técnicas: hematoxilina e eosina, tricrômica de Gomori, reticulina de Gomori e técnica de Luna e Ishack para canalículos biliares (40). Em 4 casos a técnica de Levaditi para pesquisas de leptospiras foi realizada.

Foram escolhidos exemplos típicos de biopsias hepáticas de hepatite a vírus em fase aguda, hepatite em regressão e em fase colestática, casos de hepatite biliar por obstrução extra-hepática, hepatite colangiclítica por drogas e casos de colestase intra-hepática, hepatites tóxicas, assim como exemplos de fígado normal, com vistas a se estabelecer diagnóstico diferencial histopatológico.

Analisados os diversos casos de leptospircse, juntamente com o material contrôle, os tipos lesionais foram estabelecidos sendo então o material do estudo separado por grau de lesões e uma compara ão com o aspecto clínico-evolutivo assim como no que concerne ao aspecto funcional hepático realizado na época da biopsia com a finalidade de se estabelecer estudo correlativo clínico-laboratorial e histopatológico.

\section{RESULTADOS}

Análise e comentários dos dados de função hepática

1. Análise da ictericia no material estudado.

O aparecimento da icterícia pode se: bastante precoce no decurso das leptospiroses, podendo mesmo ser notada com menos de 48 horas de início dos sintomas, como assinalado em alguns casos. Em média aparece entre o $3 .^{\circ}$ e $5 .^{\circ}$ dias de doença.

E um elemento de valor diagnóstico, principalmente quando exibe características clássicas de cúprica ou rubínica. Quando associada a sufusões hemcrrágicas conjuntivais pràticamente sela o diagnóstico de leptospirose. Icterícia com estas caracte- 
risticas clinicas estêve presente em cêrıa de $71 \%$ dos pacientes.

Devemos assinalar que após a metade ou fim da $2 .^{a}$ semana, a característica rubinica pode regredir ou ser pouco evidente, desaparecendo assim, se c caso é analisado peia $1 .^{2}$ vez nesta fase, um elemento de grande valor diagnóstico ao exame físico.

Pode atingir a intensidade máxima na $1^{\text {a }}$ semana, no entanto a grande maioria dos pacientes exibiu o maior grau no decurso da $2 .^{\mathrm{a}}$ ou $3 .^{\mathrm{a}}$ semanas de doença. Esta época coincide com a mortalidade mais elevada no curso destas infecções, entretanto não há relação direta entre intensidade da ictericia e mortalidade. Por outro lado, a morte no decurso das formas anictéricas é muito rara. Em nossa opinião a icterícia deve ser encarada como um grau maior de patogenicidade da doença e como elemento prognóstico deve ser julgada em conjunto com outros dados clínicos e laboratoriais.

Os pacientes da série que tiveram evolução fatal tinham na época do óbito 25,2 , 19,2 e $30 \mathrm{mg} \%$ de bilirrubinemia total. Desta mesma série, 6 apresentaram cifras acima de $30 \mathrm{mg} \%$ e nenhum óbito foi observado, fato que mostra que em realidade não há relação direta entre hiperbilirrubinemia e prognóstico.

A fração predcminante foi sistemàticamente a bilirrubina direta, apenas 1 caso (n. 1) apresentou na $3 .^{\mathrm{a}}$ semana predomínio da indireta. Nossa experiência com material muito maior que o do presente estudo mostrou-nos que a fração predominante é sempre a da bilirrubina direta e que excepcionalmente a indireta pode predominar.

A regressão da icterícia de um modo geral é bastante lenta e progressiva. Nesta fase pcde ocorrer elevação da bilirrubina em relação a niveis prévios, no entanto êste fato é discreto e infreqüente. $A$ análise do comportamento gráfico das bilirrubinas demonstra bem êstes fatos.

Nos pacientes 9,11 e 14, a bilirrubina sòmente voltou a níveis normais após a $144^{\mathrm{a}}$, $15 .^{\mathrm{a}}$ e $10 .^{\mathrm{a}}$ semanas, respectivamente (Quadro IX).

Em alguns pacientes nos quais utilizamos corticóides notamos uma queda nítida e mais rápida das taxas de bilirrubina. Este fato foi nitidamente observado na paciente n. ${ }^{\circ} 37$. Esta capacidade de redução da icterícia nas leptospiroses por parte dcs corticóides deve-se sem dúvida alguma à díminuição da colestase intra-hepática, fenômeno evidente nesta patologia.

Ramos Morales assinalou icterícia de variável intensidade em aproximadamente $50 \%$ dos casos e o tempo médio de aparecimento foi no $5 .^{\circ}$ dia em $65 \%$ dos pacientes e em tôrno do $7.9 \mathrm{em} \mathbf{9 0 \%}$. Os valôres mais altos de bilirrubina sérica foram observados dentro dos primeircs 7 dias após o aparecimento da icterícia em $\mathbf{8 0 \%}$. Esta persistiu em média 32 dias com limites extremos de 1 a 70 dias. Não foi assinalado prurido e a urina foi geralmente positiva para bile. Ligeira a moderada hepatomegalia foi enccntrada em $70 \%$ dos casos. Êste achado ocorreu com a mesma freqüência nos casos com e sem icterícia. Fezes de coloração esbranquiçada foram observadas transitòriamente em 4 dos casos ictéricos. Demonstrou um aumento frequiente na fração da bilirrubina de $1 \mathrm{~min}$. Em seu trabalho o maior grau de disfunção hepática ocorreu em tôrno da $2 .^{a}$ semana de doença, evidenciado pelos valôres máximos de bilirrubina e pelas alterações na esterificaçãc do colesterol. Evidência de disfunção hepática através dados laboratoriais foi assinalada em ambos, tanto ictéricos como anictéricos. Finaliza o autor apontando que o mais impcrtante fator na patogênese da icterícia nas leptospiroses é uma diminuição da capacidade funcional do fígado (34)

Austoni e Treu, em 7 pacientes com icterícia intensa acharam $16,4 \mathrm{mg} \%$ como valor máximo. Em 12 de forma leve e de média gravidade, o teor mais elevado foi de 6,1 e em 9 anictéricos, os resultados foram normais. (8).

Machado da Silva em estudo de bilirrubinas do sôro de 23 pacientes em periodos diversos da doença, encontrcu aumento em todos. Em 15 predominou a bilirrubina de reação direta e em 5 casos houve predomínio discreto da fração indireta. No entanto em 1 dêstes pacientes a diferença alcançou $10 \mathrm{mg}$ de bilirrubina indireta para a direta com 6 dias de doença. Em 4 enfermos houve aumento idêntico de ambas frações. O aumento do referido pig- 
Q U A D R O I X

Estudo funcional hepático - billirrubinemia total/direta ( $\mathrm{mg} \%$ )

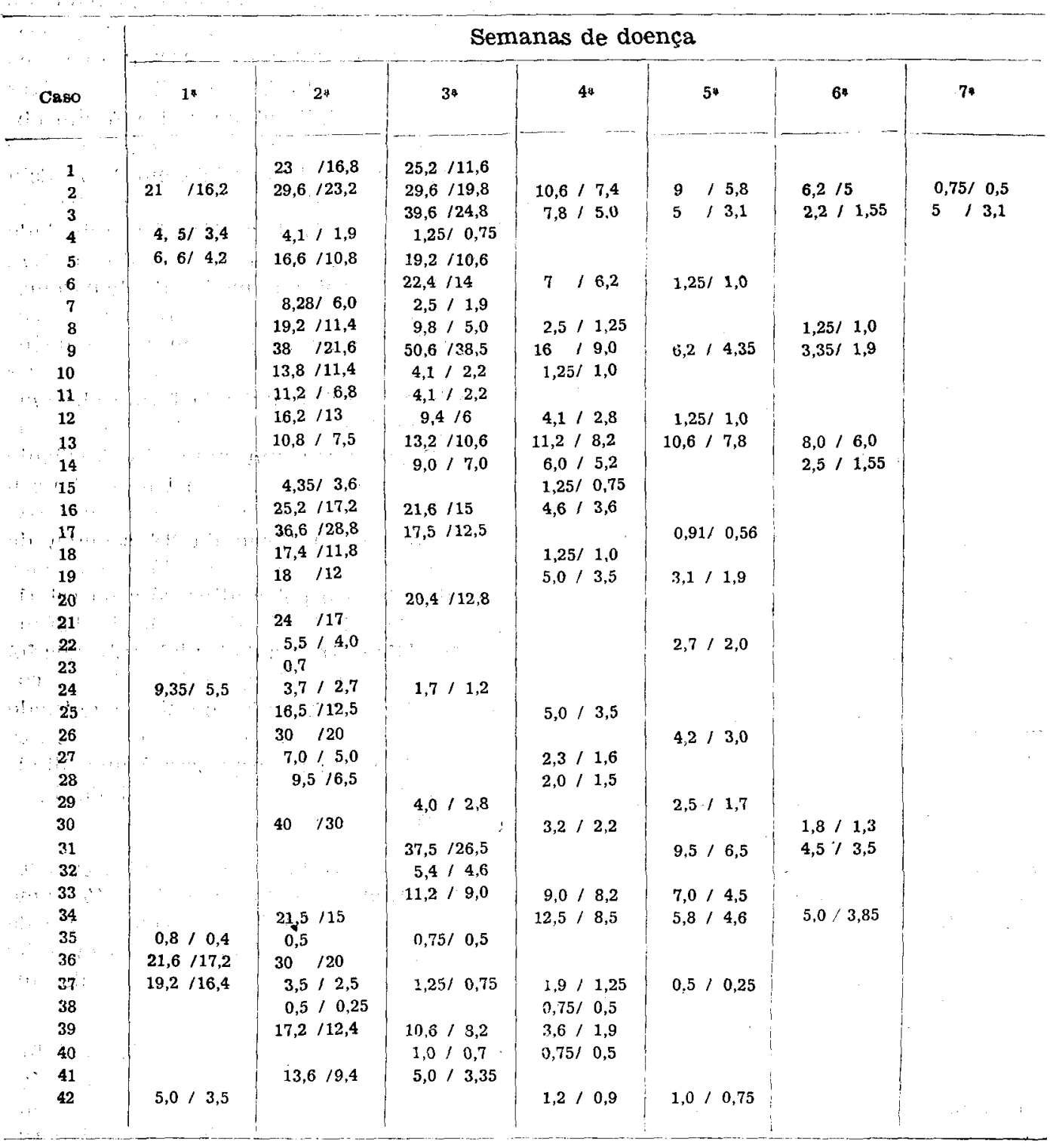


mento processou-se desde o $44^{\circ}$ dia de doença, geralmente demorando a retornar aos niveis normais (27).

Em trabalho prévio no qual assinalamos a icterícia em 14 casos, constatamos também que a fração predominante foi a direta e a intensidade mínima de bilirrubinemia fci de 2,5 e a máxima de $47,2 \mathrm{mg} \%$ (32) .

San Juan e cols. em análise de $17 \mathrm{pa}-$ cientes também assinalaram franco predomínio da fração direta (36).

Pereira da Silva e cols. em 16 pacientes encontram valôres predominantes da fração direta sendo o mínimo de bilirrubinemia total assinalado de 2,6 e o máximo de $\mathbf{7 1 , 9}$ $\mathrm{mg} \%$. A duração da icterícia neste material apresentou tempo médio de 25 dias e o início ocorreu em tôrno do $60^{\circ}$ dia de doença (29) .

Frizamos que uma percentagem grande de pacientes ictéricos no decorrer da evolução clínica apresenta prurido às vêzes muito intenso e esta queixa tem sido bastante freqüente em nossas observações.

\section{Análise das transaminases}

A elevação das transaminases é öjscreta, nunca atinge cifras elevadas como acontece nas hepatites infecciosas. Na maioria das vézes a TGP apresenta cifras superiores a TGO e em nenhuma ocasião encontramos cifras superiores a $250 \mathrm{u}$. No material analisado pràticamente im $100 \%$ dos casos houve eleva ão discreta ou moderada nas dosagens destas enzimas. Em apenas 2 casos a TGP mostrcu-se cm níveis máximos da normalidade, porém a sua. determinação só foi realizada em 1 ocasião.

Os valôres não muito elevados estão em perfeita consonância com cs achados histopatológicos desde que a necrose herisira não foi acentuada em nenhum caso

Dos 4 pacientes anictéricos (casos 23, 35,38 e 40 ) 2 apresentaram elevações significativas nos níveis de transaminases ica$\operatorname{sos} 35$ e 40).

O compcrtamento das transaminares nas leptospiroses tem sido bastante eztiudađo por vários autores $(19,20,29,32,36)$.

Pereira da Silva e cols. em análise de 16 pacientes encontram alterações em 12 ca- racterizadas por elevações discretas, divergindo de nossa experiência na série dêste autor houve moderado predomínio da TGO em 7 pacientes. (29).

As alterações nas transaminases do material analisado poderão ser melhor avaliadas no Quadro X.

\section{Análise da fosfatase alcalina (Quadro $X I)$}

Em 36 pacientes as cifras situaram-se acima dos limites superiores da normalidade, elevação acima de $20 \mathrm{u}$ KA occrreu em 16 .

Elevações bem expressivas, isto é, acima de $30 \mathrm{u}$, indicando um componente obstrutivo, foram assinaladas 8 vêzes.

A cifra máxima da fosfatase alcalina pode ser observada ao nível da $1 .^{\mathrm{a}}$ semana, no entanto seus valôres mais elevados predcminam em tôrno da $2 .^{a}$ e $3 .^{a}$ semanas. Fatos análogos aconteceram em relação ao comportamento das bilirrubinas, demonstrando um componente obstrutivo intra-hepático na gênese da icterícia. Existem no entanto alguns casos que revelam discrepâncias em relação ao comportamento da bilirrubina e fosfatase alcalina, como pode ser assinalado no caso $15 \mathrm{em}$ que na $4 .^{\mathrm{a}}$ semana exibia 27 u $\mathrm{KA}$ de fosfatase alcalina e estava pràticamente $\mathrm{ccm}$ cifras normais de bilirrubina. Fatos semelhantes foram evidenciados nas formas anictéricas nas quais a fosfatase alcalina atingiu cifras de 20 e 30 u respectivamente (casos 23 e 35).

Chamamos a atenção para o fato de que, se alguns dêstes pacientes são hcspitalizados ao fim da $2^{a}$ ou $3 .^{a}$ semana de doença, fase em que os ferômenos septicêmicos geralmente estão ausentes, houve regressão da congestão ocular e a icterícia perdeu sua característica coloração, tais casos poderão ser interpretados como portadores de icterícia obstrutiva face os dados de exame físico e laboratoriais. $A$ história clínica deverá ser bem realizada no sentido de um diagnóstico diferencial e deverá conter perguntas relativas à caracterização de uma leptospirose.

Êstes exemplos já foram por nós vividos e despertamos a atenção para que estas infecções sejam incluídas mais freqüente- 
Q U A D R O X

Estudo funcional hepático - transaminases TGO/TGP (u. Karmen)

\begin{tabular}{|c|c|c|c|c|c|c|c|c|c|c|}
\hline \multirow[b]{2}{*}{ Caso } & \multicolumn{10}{|c|}{ Semanas de doença } \\
\hline & 18 & $2^{9}$ & & 3 & $4^{9}$ & & $5^{3}$ & & $6^{*}$ & 79 \\
\hline 1 & & $31,5 / 55$ & 30 & $/ 51$ & & & & & & \\
\hline 2 & $16 / 45$ & $31,5 / 39$ & 26 & 149 & $26 / 55$ & 20 & 155 & 40 & $/ 81$ & $8,5 / 31,5$ \\
\hline 3 & & & 64 & $/ 102$ & $30 / 66$ & 40 & $/ 89$ & 36 & $/ 51$ & \\
\hline 4 & $155 / 112$ & $20 \quad / 55$ & 12 & $/ 31,5$ & & & & & & \\
\hline 5 & & $27 / 50$ & 33 & 148 & & & & & & \\
\hline 6 & & & 26 & 143 & $8,5 / 31,5$ & 33 & $/ 51$ & & & \\
\hline 7 & & $31 \quad / 74$ & 33 & $/ 55$ & $8,5 / 31,5$ & & & & & \\
\hline 8 & & $30 / 60$ & 64 & 1129 & $40 / 66$ & & & 26 & 160 & \\
\hline 9 & & $30 / 59$ & 26 & $/ 51$ & $\begin{array}{ll}40 & 700 \\
26 & 159\end{array}$ & 40 & $/ 78$ & 40 & 181 & \\
\hline 10 & & $35 \quad / 62$ & 36 & $/ 66$ & $20 \quad / 43$ & & & & & \\
\hline 11 & & $26 \quad 159$ & 40 & 181 & & & & & & \\
\hline 12 & & $95 / 80$ & 12 & $/ 35$ & $20 \quad / 39$ & & & & & \\
\hline 13 & & $75 \quad / 224$ & 40 & 174 & $12 / 19$ & 43 & $/ 59$ & 40 & $/ 89$ & \\
\hline 14 & & & 40 & $/ 81$ & $26 / 55$ & & & 26 & $/ 55$ & \\
\hline 15 & & $46 \quad / 102$ & & & $100 / 189$ & & & & & \\
\hline 16 & $45 / 45$ & $21,5 / 43$ & 20 & 143 & $76 / 115$ & & & & & \\
\hline 17 & & $57 \quad / 89$ & & & & & & & & \\
\hline 18 & & $100 / 159$ & & & $26 / 51$ & - & $/ 26$ & & & \\
\hline 19 & & $-/ 90$ & & & -160 & 20 & $/ 59$ & & & \\
\hline 20 & & & 30 & 160 & & & & & & \\
\hline 21 & & -140 & & & & & & & & \\
\hline 22 & & -160 & & & & - & 180 & & & \\
\hline 23 & & -140 & & & & & & & & \\
\hline 24 & $227 / 91$ & -145 & & & & & & & & \\
\hline 25 & & $-/ 100$ & & $-/ 30$ & -160 & & & & & \\
\hline 26 & & -180 & & & & - & $/ 40$ & & & \\
\hline 27 & & -160 & & & -145 & & & & & \\
\hline 28 & & $-/ 50$ & & & -140 & & & & & \\
\hline 29 & & (10 & & $-/ 180$ & & 一 & 140 & & & \\
\hline 30 & & $-/ 100$ & & & $-/ 50$ & & & - & -135 & \\
\hline 31 & & & & -160 & & - & $/ 50$ & - & -140 & \\
\hline 32 & & & 57 & $/ 102$ & & & & & & \\
\hline 33 & & & 36 & $/ 66$ & $50 / 109$ & - & 170 & & & \\
\hline 34 & & -160 & & & $-/ 50$ & 30 & 157 & 64 & $/ 115$ & \\
\hline 35 & $8,5 / 31,5$ & -160 & 40 & $/ 81$ & & & & & & \\
\hline 36 & $60 / 122$ & $30 / 59$ & & & & & & & & \\
\hline 37 & $26 / 51$ & $31,5 / 66$ & & $5 / 35$ & $28 \quad / 39$ & 18 & 131,5 & & & \\
\hline 38 & & $20 / 43$ & & $3 / 66$ & $26 / 47$ & & & & & \\
\hline 39 & & $20 / 41$ & - & 1100 & $68 \quad / 129$ & & & & & \\
\hline 40 & & & & & $95 \quad / 220$ & & & & & \\
\hline 41 & & $20 / 39$ & 16 & $/ 35$ & & & & & $\rightarrow$ & \\
\hline 42 & -75 & & & & $-/ 100$ & 12 & $/ 39$ & & 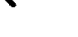 & \\
\hline
\end{tabular}


Q U A D R O X I

Estudo funcional hepático - fosfatase alcalina (U.K.A.)

Semanas de doença

\begin{tabular}{|c|c|c|c|c|c|c|c|}
\hline \multirow[b]{2}{*}{ Caso } & \multicolumn{7}{|c|}{ Semanas de doença } \\
\hline & $1 .^{a}$ & $2 .^{\mathrm{a}}$ & $3 .^{a}$ & $4 .^{a}$ & $5 .^{a}$ & $6 .^{\mathrm{a}}$ & $7 .^{a}$ \\
\hline 1 & & 44 & 14 & & & & \\
\hline 2 & & 12 & 13 & 13 & 10 & 24 & 18 \\
\hline $\begin{array}{l}3 \\
4\end{array}$ & & & 56 & 19 & 22 & 24 & 24 \\
\hline $\begin{array}{l}4 \\
5\end{array}$ & & 10 & & & & & \\
\hline 6 & & & 8 & & & & \\
\hline 7 & & 6 & 20 & . & & 10 & \\
\hline $\begin{array}{l}8 \\
9\end{array}$ & & 27 & 23 & 12 & & 17 & \\
\hline $\begin{array}{r}9 \\
10\end{array}$ & & 9 & 43 & 43 & 40 & $\mathbf{2 3}$ & \\
\hline $\begin{array}{l}10 \\
11\end{array}$ & & 8,3 & 9 & 9 & & & \\
\hline $\begin{array}{l}11 \\
12\end{array}$ & & 15 & 13 & & & & \\
\hline $\begin{array}{l}12 \\
13\end{array}$ & & 13 & 5 & 13 & & & \\
\hline $\begin{array}{l}13 \\
14\end{array}$ & & 15 & 29 & 18 & 15 & 36 & \\
\hline 15 & & 17 & $\begin{array}{r}7 \\
48\end{array}$ & $\begin{array}{l}17 \\
27\end{array}$ & & 10 & \\
\hline 16 & & 16 & $\begin{array}{c}70 \\
9\end{array}$ & 20 & & & \\
\hline 17 & & 55 & & & 25 & & \\
\hline 18 & & 32 & & 15 & & & \\
\hline 19 & & 30 & & 13 & 17 & & \\
\hline $\begin{array}{l}20 \\
21\end{array}$ & & 13,5 & 10 & & & & \\
\hline 22 & & 18 & & & 18 & & \\
\hline $\begin{array}{l}23 \\
24\end{array}$ & 30 & 20 & & & & & \\
\hline 25 & & 12 & 18 & 10 & & & \\
\hline 26 & & 10 & & & 9 & & \\
\hline 27 & & 13 & & 15 & & & \\
\hline $\begin{array}{l}28 \\
29\end{array}$ & & 14 & & 11 & & & \\
\hline $\begin{array}{l}29 \\
30\end{array}$ & & 10 & 12 & 13 & 13 & & \\
\hline 31 & & 10 & 15 & 13 & 20 & 11 & \\
\hline 32 & & & 16 & & & & \\
\hline 33 & & & 16 & 21 & 15 & & \\
\hline 34 & & 15 & & 16 & 17 & 22 & \\
\hline 35 & 30 & 15 & 21 & & & & \\
\hline $\begin{array}{l}36 \\
37\end{array}$ & $\begin{array}{l}13 \\
37\end{array}$ & 12 & 12 & 10 & 11 & & \\
\hline 38 & & 6 & & 16 & & & \\
\hline 39 & & 21 & 20 & 19 & & & \\
\hline $\begin{array}{l}40 \\
41\end{array}$ & & 14 & $\begin{array}{l}17 \\
12\end{array}$ & 15 & & & \\
\hline 42 & 10 & & & 10 & 8 & & \\
\hline
\end{tabular}


Q U A D R O X I I

Estudo funcional hepático - colesterol total (mg\%)

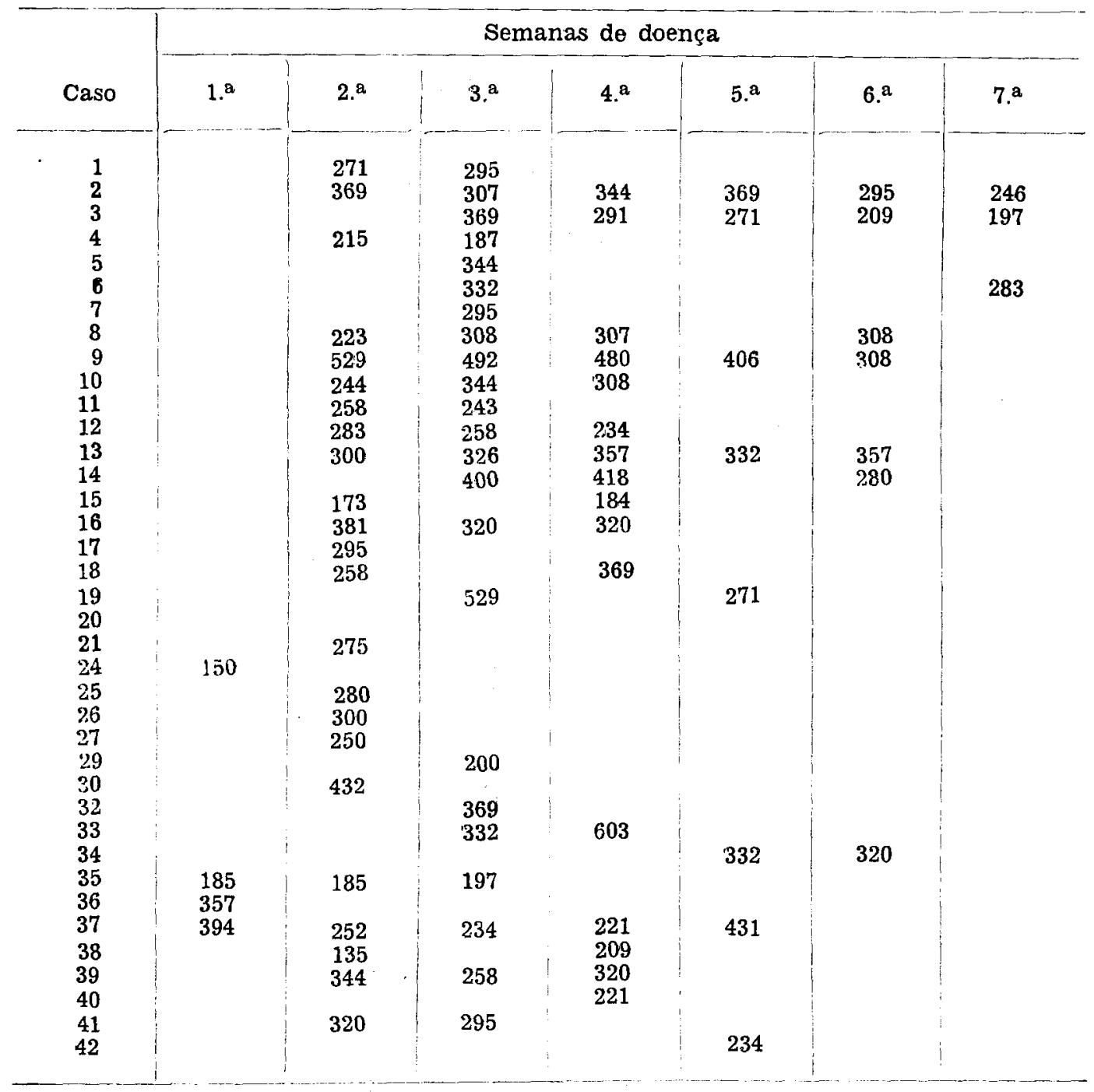

mente no diagnóstico diferencial das icterícias de origem parenquimatosa ou obstrutiva $(18,32,33)$.

Austoni achou valôres baixos desta enzima, os quais podiam persistir até a convalescença $(9)$.

Ramos Morales e cols. assinalam uma anormalidade em 5 de 30 pacientes ictéri$\cos \mathrm{e}$ em 2 anictéricos (34).

Machado da Silva determinou-se em 12 pacientes e sòmente em 2 ocasiōes enccntrou elevação (27).

Rios Gonçalves e cols. em análise de 14 casos encontrou valôres acima da norma- lidade em 8 sendo o máximo assinalado de $26 \mathrm{u} \mathrm{KA}$ (32).

Pereira da Silva e cols. realizando em 13 pacientes a mesma análise, encontram uma pequena elevação da fosfatase alcalina em 3 (29).

\section{Análise do colesterol (Quadro XII)}

A dosagem do colesterol foi realizada em 38 pacientes. Em 27 as cifras foram elevadas. Em 13, valôres superiores a $\mathbf{3 5 0}$ mg\% foram cbtidos. As cifras máximas são observadas em tôrno da $2 .^{\mathrm{a}}$ e $3 .^{\mathrm{a}}$ semanas 
e correm de um modo geral paralelas a bilirrubina e a fosfatase alcalina. $O$ valor máximo observado foi de $603 \mathrm{mg} \%$.

Sua elevação em conjunto com as alteraçóes da bilirrubina e da fcsfatase alcalina cemonstram cue existe um nítido componente obstrutivo' intra-hepático no aspecto funcional.

Do ponto de vista histofuncional existe na maioria das vêzes uma perfeita harmcnia desde que a colestase intra-hepática foi elemento importante nos achados de histopatologia.

Para Austoni o colesterol total mantemse baixo (9), o mesmo fato ocorreu na série de Edelweiss (16).

$\mathrm{Na}$ experiência de Chinn e col. (13) e Ramos Morales (34) estêve dentro dos limites normais.

Machado da Silva em 12 encontrou um aumento em 5 casos sendo o valor máximo de $280 \mathrm{mg} \%$ (27).

San Juan e ccls. em 17 casos encontrou elevar ão acima de $270 \mathrm{mg} \%$ em 10 sendo que em 3 a colesterolemia ultrapassou a $400 \mathrm{mg} \% \quad(10)$

\section{Análise da atividade protrombinica (Quadro XIII)}

Apenas 3 pacientes não realizaram atividade protrombínica. Em 22 foram obtidas cifras inferiores a $60 \%$.

Nos casos ncs quais dosagens semanais foram feitas (casos 2, 3, 8, 9, 13 e 16) os valôres mínimos foram registrados em tôrno da $2 .^{a}$ e $3 .^{a}$ semanas. $O$ valor mínimo obtido foi de $20 \%$. Nos pacientes $2,3,4,8$, 9,13 e 16 nos quais a vitamina $\mathrm{K} 1 \mathrm{fci}$ administrada não observamos resposta. Outros pacientes receberam a mesma medicação porém por falta de exames seriados próximos, não pudemos fazer uma apreciação real de sua resposta. Êstes fatos estãc de pleno acôrdo com outros assinalados em estudos prévios $(32,36)$.

Não há dúvida que algum grau de disfunção da célula hepática ocorre nesta patolcgia. Êstes distúrbios ficam bem evidenciados não sòmente na baixa da atividade protrombínica que ocorreu pràticamente em todos os doentes como na carência de resposta naqueles em que uma terapêtica foi instituída.

Em muitos cascs analisados a queda da protrombina foi o elemento que não per- mitiu que realizássemos a biopsia hepática em épocas mais recentes. Por outro lado a realização de biopsias em fases mais tardias da dcença serviram para nos mostrar que lesões histológicas podem ser encontradas com história clínica datando de mais de 30 dias de doença. Na série, 14 casos fizeram biopsia hepática com mais de 1 mês do início dos sintomas e muitos dêles evidenciavam alterações histológicas compatíveis $\mathrm{ccm}$ leptospirose (casos $6,7,8,9,12$, $14,20,21,22,26,30,31,34$ e 37$)$.

\section{Análise das proteinas totais e frações (Quadro XIV)}

Dos 27 pacientes que realizaram dosagem de proteinemia total, 15 apresentaram cifras inferiores a $6 \mathrm{~g} \%$. De 26 que realizaram dosagens de albumina sérica, 23 apresentaram níveis inferiores a $4 \mathrm{~g} \%$ e alguns tiveram cifras bastante baixas.

Êstes dados são também favoráveis ao fato de que um deficit da célula hepática ocorre nesta patologia.

o comportamento das globulinas revelou 9 pacientes com discreta elevação acima de $3 \mathrm{~g} \%$.

Machado da Silva em dosagens proteicas de 25 doentes, a exceção de um, encontrou baixa das albuminas e aumento das globulinas (27)

Em trabalho anterior (36) em que a proteinemia foi realizada em 15, hipoalbuminemia entre 1,83 e 3,40 e globulinemia acima de 2,5 foram encontradas em 10 casos.

\section{Análise da eletroforese proteica (Qua- dro $X V)$}

23 pacientes realizaram êste exame: 6 tiveram cifras abaixo de $6 \mathrm{~g} \%$ de proteinemia total, hipcalbuminemia estêve $\epsilon \mathrm{m}$ níveis inferiores a normalidade em todos os pacientes e em alguns houve marcada queda da albumina.

Comportamento das globulinas:

Análise de alfa $1-23$ apresentaram cifras superiores a $0,3 \mathrm{~g} \%$.

Alfa 2 - todos os pacientes mostraram valôres de alfa 2 supericres aos considerados normais e em 7 as cifras foram além de $1 \mathrm{~g} \%$ (casos $8,9,10,16,36,38$ e 40 ).

Beta - 14 pacientes apresentaram valôres superiores a $0,90 \mathrm{~g} \%$. 
Q U A D R O X I I I

Estudo funcional hepático - atividade protrombínica (\%)

\begin{tabular}{|c|c|c|c|c|c|c|c|}
\hline \multirow[b]{2}{*}{ Caso } & \multicolumn{7}{|c|}{ Semanas de doença } \\
\hline & $1 .^{\mathrm{a}}$ & $2 .^{a}$ & $3 .^{\mathrm{a}}$ & $4 .^{\mathrm{a}}$ & $5 .{ }^{2}$ & $6 .^{a}$ & $7 .^{\mathrm{a}}$ \\
\hline $\begin{array}{r}1 \\
2 \\
3 \\
4 \\
6 \\
7 \\
8 \\
9 \\
10 \\
11 \\
12 \\
13 \\
14 \\
15 \\
16 \\
17 \\
18 \\
19 \\
21 \\
22 \\
23 \\
24 \\
25 \\
26 \\
27 \\
28 \\
29 \\
30 \\
31 \\
32 \\
33 \\
34 \\
35 \\
36 \\
37 \\
38 \\
39 \\
41 \\
42\end{array}$ & $\begin{array}{l}55 \\
84 \\
\\
55\end{array}$ & $\begin{array}{l}60 \\
30 \\
\\
40 \\
50 \\
60 \\
\\
40 \\
\\
60 \\
40 \\
38 \\
\\
72 \\
62 \\
\\
\\
84 \\
63 \\
38 \\
\\
84 \\
72\end{array}$ & $\begin{array}{l}30 \\
55 \\
30 \\
50 \\
30 \\
40 \\
40 \\
20 \\
\\
50 \\
\\
40 \\
50 \\
60\end{array}$ & $\begin{array}{c}60 \\
35 \\
\\
\\
60 \\
35 \\
35 \\
60 \\
\\
\\
60 \\
60 \\
100 \\
65 \\
59 \\
59 \\
\end{array}$ & $\begin{array}{l}45 \\
50 \\
\\
60 \\
50\end{array}$ & $\begin{array}{l}72 \\
72\end{array}$ & $\begin{array}{l}80 \\
40\end{array}$ \\
\hline
\end{tabular}

Gama - 15 tiveram cifras superiores a $1,4 \mathrm{~g} \%$. Em 10 pacientes a eletroforese proteica foi realizada na $3 .^{a}$ semana de doença e alterações dêste exame podem ser notadas em prazo tão longo de até 2 meses após o início dos sintomas, como sucedeu com o caso 14. Embora não seja especifica demonstra um deficit na sintese da albumina e elevaçóes pronunciadas de alfa 2 e de gama globulinas.

Machado da Silva realizando eletroforese $\mathrm{em} 12$ pacientes, encontrou baixa da albumina e elevação das globulinas, elemento constante foi o aumento da alfa 2; também assinalou um aumento da gama e beta globulinas e em 6 elevação de alfa 1 (27).

San Juan em análise eletroforética de 10 pacientes registrou hiperglobulinemia em todos com aumento de alfa $1 \mathrm{em} 2$ ocasiões, alfa 2 em 3 e gama em 5 (36).

Análise das provas de turvaçäo e floculação (Quadro XVI)

32 fizeram turvação do timol, floculação do timol, turvação do sulfato de zinco e reação da gamaglobulina. Em apenas 6 pacientes estas provas se mostraram negativas. Em 12 apresentaram poucas alterações e em 14 elas foram consideradas muito alteradas. 


\section{Q U A D R O X I V}

\section{Estudo funcional hepático - proteinas totais - g\% (albumina e globulina)}

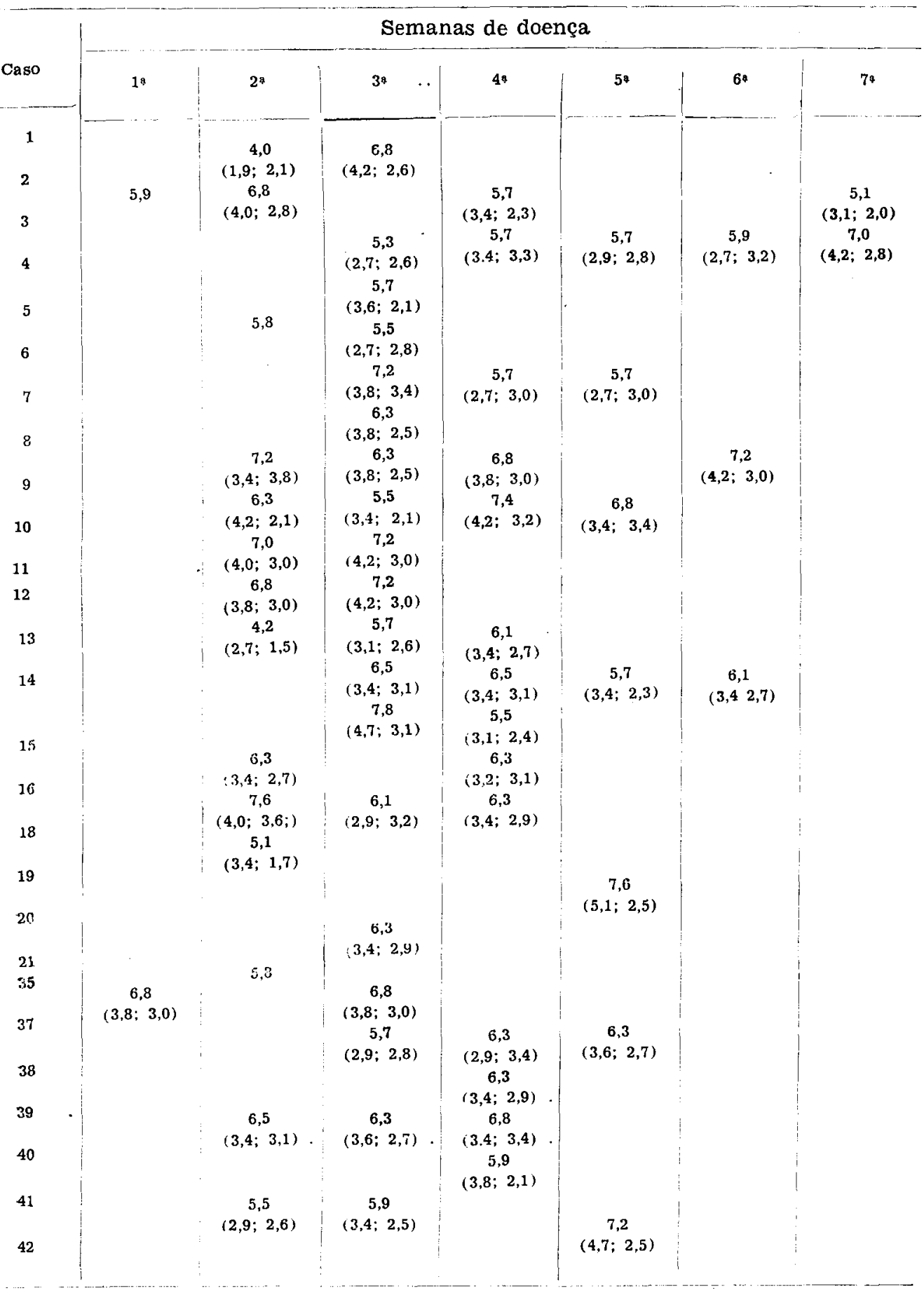


As alteraçōes mais importantes foram também assinaladas em tôrno da $2 .^{a}$ e $3 .^{a}$ semanas podendo no entanto tais alterações persistirem até a $5^{a}$ semana de doença.

Machado da Silva comentando alterações em 24 pacientes que realizaram a cefalina colesterol, assinalou positividade de + em 3 casos e de $++\mathrm{a}+++$ em 16 , e em 4 a prova foi negativa (27).

Em 64 enfermos ictéricos de Ramos-Morales e cols., esta reação mostrou-se anormal em 52 e em 14 dos 21 anictéricos (34).

A turvação do timol em 83 casos de Ramos-Morales se mostrou anormal em 7 (34).

Machado da Silva encontrou alterações nos 21 casos analisados (27).

Em relação a prova de Kunkel, Machado da Silva em 21 casos encontrou um aumento acentuado na $1 .^{\text {a }}$ semana em 3 , na $2 .^{\mathrm{a}}$ em 9 e mais tardiamente em 12 (27).

Fereira da Silva e cols., em 15 pacientes nos quais realizam as provas de turvação e floculação, assinalam que na maioria dos casos foram pouco alteradas e em apenas 3 foram consideradas bastante alteradas (29).

San Juan, em 17, encontrou dados inconsistentes e variados (36).

\section{Análise da desidrogenase láctica}

Em apenas 2 pacientes (casos 15 e 33) foram realizadas dosagens da desidrogenase fáctica que se mostrou em níveis superiores da normalidade nas 2 ocasiões .... ( 738 u e 682 u).

\section{Prova da bromossulfaleina}

Realizada em 4 pacientes (casos 9, 14, $15,16)$. O paciente $n .09$ realizou-a com 2 meses e meio de doença e o resultado foi normal. O de n. ${ }^{\circ} 14$ com 103 dias de doença, também com resultado normal. O de n. 15 executou-a com 1 mês apenas de doença, época em que a bilirrubina estava em níveis normais, tendo apresentado discreto deficit na excreção ao fim de $45 \mathrm{mi}-$ nutos $(12,5 \%)$. E por fim o de n. ${ }^{\circ} 16$ fêz com 57 dias de doença sendo o resultado normal.

\section{Q U A D R X V}

Estudo funcional hepático - Eletroforese de proteinas ( $\mathrm{g} \%$ )

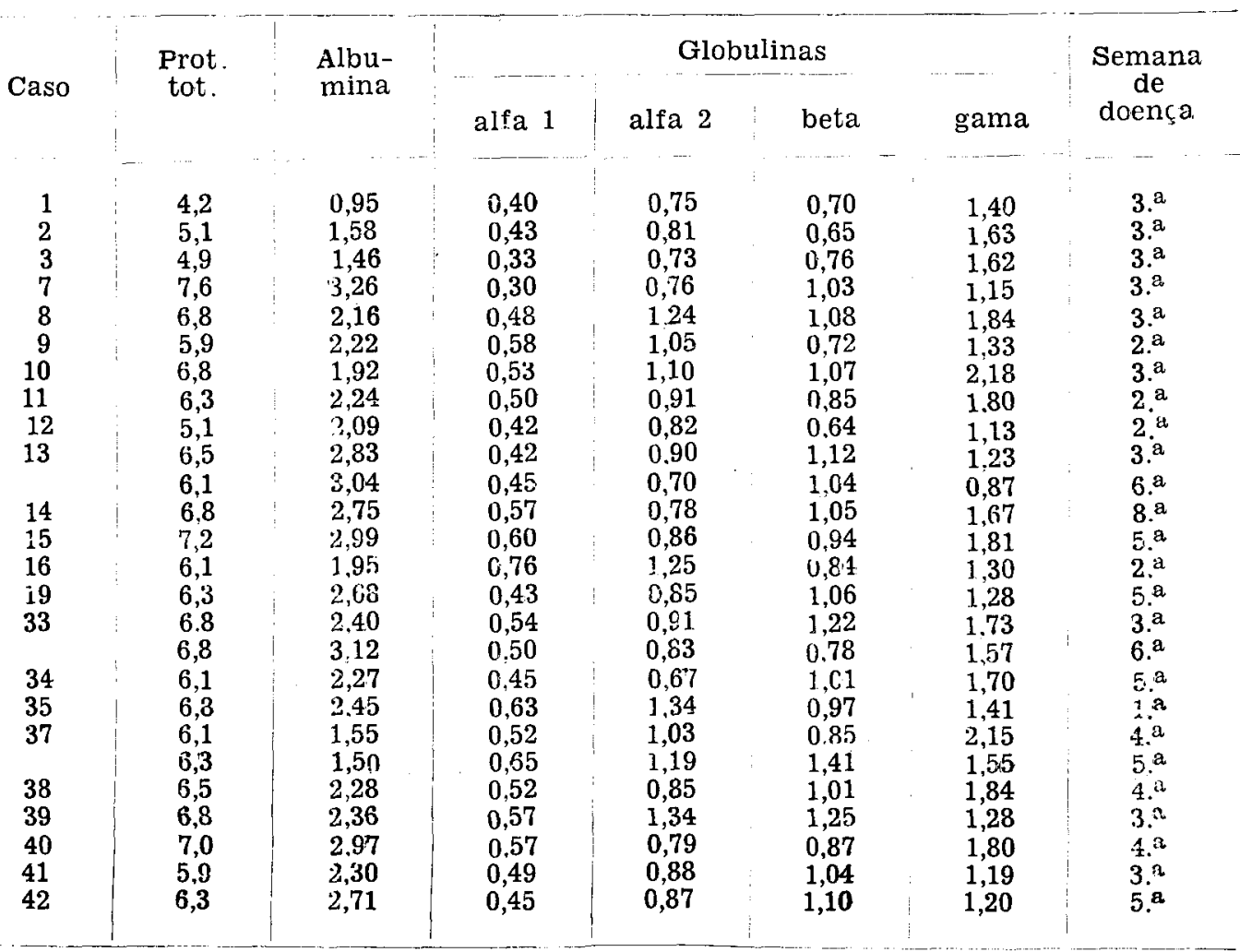


Q U A D R O X V I

Estudo funcional hepático - provas de turvação e floculação

\begin{tabular}{|c|c|c|c|c|c|c|c|}
\hline \multirow[b]{2}{*}{ Caso } & \multicolumn{7}{|c|}{ Semanas de doença } \\
\hline & $1 .^{\mathrm{a}}$ & $2 .{ }^{a}$ & $3 .^{\mathrm{a}}$ & $4 .^{\mathrm{a}}$ & $5 .^{a}$ & $6 .^{\mathrm{a}}$ & $7 .^{2}$ \\
\hline $\begin{array}{r}1 \\
2 \\
3 \\
4 \\
5 \\
6 \\
7 \\
8 \\
9 \\
10 \\
11 \\
12 \\
13 \\
14 \\
15 \\
16 \\
17 \\
18 \\
19 \\
21 \\
22 \\
32 \\
33 \\
34 \\
35 \\
36 \\
37 \\
38 \\
39 \\
40 \\
41 \\
42\end{array}$ & $\begin{array}{c}\mathbf{N} \\
++ \\
++\end{array}$ & $\begin{array}{c}-++ \\
++ \\
+ \\
+ \\
\mathbf{N} \\
++ \\
++ \\
+ \\
+ \\
++ \\
\\
+ \\
++ \\
++ \\
++ \\
\mathbf{N} \\
+ \\
+\end{array}$ & $\begin{array}{c}++ \\
++ \\
++ \\
\mathrm{N} \\
++ \\
+ \\
+ \\
+ \\
++ \\
+ \\
+ \\
++ \\
+ \\
++ \\
++ \\
+ \\
\\
+ \\
++ \\
+ \\
\mathrm{N} \\
+ \\
++ \\
+\end{array}$ & $\begin{array}{l}\mathbf{N} \\
+ \\
\mathbf{N}\end{array}$ & $\begin{array}{c}++ \\
+\end{array}$ & $\begin{array}{l}\mathbf{N} \\
+\end{array}$ & $\mathbf{N}$ \\
\hline
\end{tabular}

Nota: $\mathbf{N}-$ normal, +- pouco alteradas, ++- muito alteradas.

\section{Análise e resultados da patologia}

Foram encontradas lesões histopatológicas de intensidade e tipos variáveis em 38 casos, em 4 que correspondiam a forma anictérica da doença não foram evidenciadas lesōes.

Em 10 casos as alterações histopatológicas foram consideradas discretas, em 15 moderadas e em 12 acentuadas.

Em todos os casos em que alterações foram descritas, houve lesões ao nivel do centro do lóbulo hepático mais intensamente em tôrno das veias centro-lobulares, caracterizadas por tortuosidade das traves hepáticas com dissociação das fileiras hepatoci- tárias e presença de colestase, variando desde pigmento biliar intra-hepatocitário e intra-kupfferiano até a presença de trombos biliares esparsos ou freqüentes, com distorção do sistema canalicular e com a formação de divertículos canaliculares, fato bem caracterizado pela técnica para canalículos biliares de Luna e Ishack (25).

Graus variáveis de degenerações hepatocitárias foram verificadas em todos os casos compreendendo, desde tumefação hidrópica, variação de volume e forma hepatocitária com degeneração hialina citoplasmática até a formação. de corpúsculos hialinos tipo Councilman e hepatócitos atróficos, hialinos com núcleos hipercorados, 


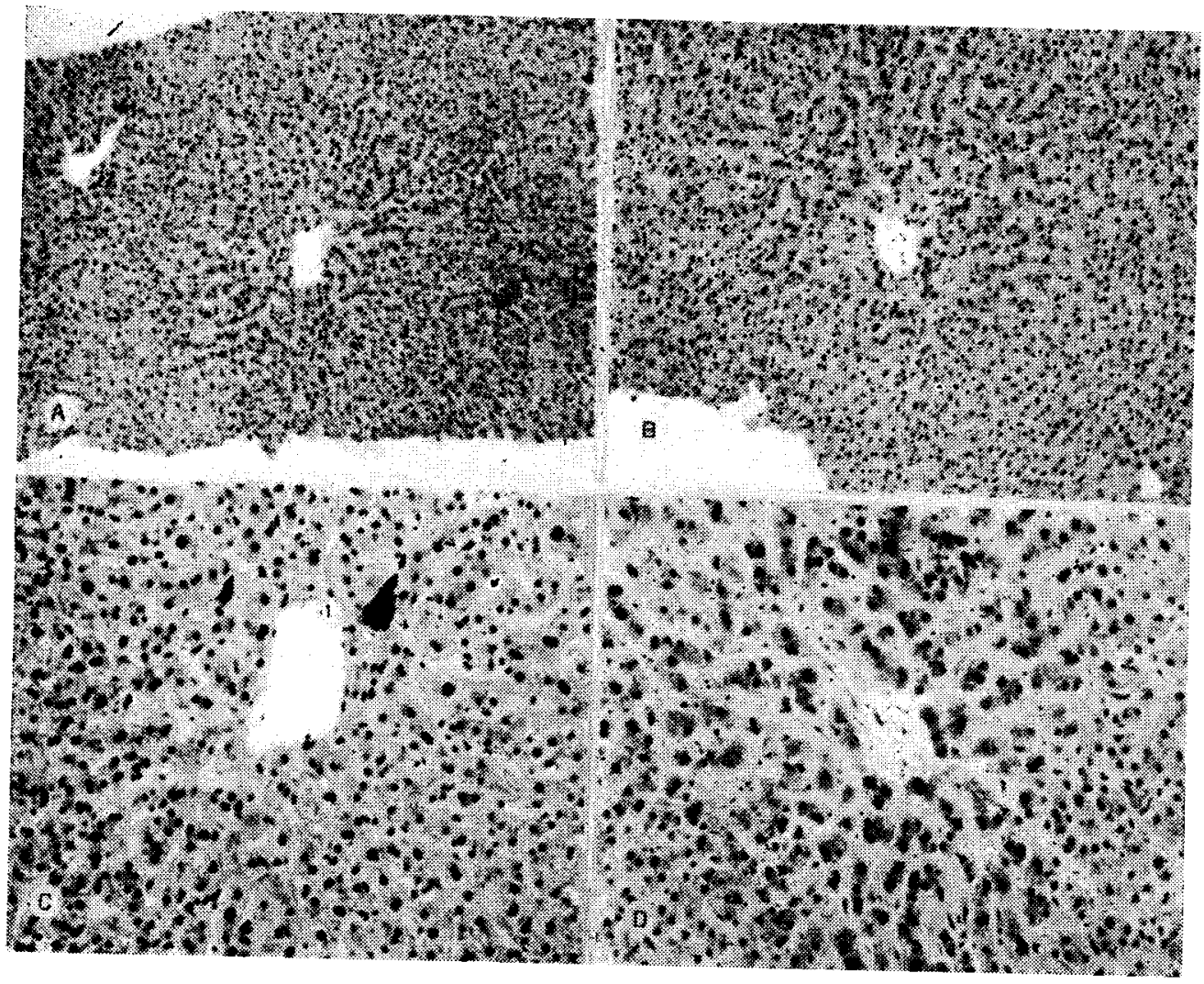

FIGURA $1-\operatorname{Em}$ A., B e C, material obtido por punção bipósica hepática onde se nota loca lizaçāo centrolobular da lesāo com dłlatação veno-sinusoidal e desarranjo locatraves hepáticas. Em D, material obtido por necropsia, notando-se a mesma lesão centrolobular, com grande acentuaçăo da dissociaçáo das flleiras hepatócitárias. 
irregulares ou mesmo picnóticos. Na grande maioria dos casos, sobretudo nas lesões ditas acentuadas, verificava-se regeneração hepatocitária, percebendo-se hepatócitos com 2 núcleos, com hipercromasia e hipertrofia nuclear, ao lado de basofilia relativa citoplasmática. As células de Kupffer além de apresentarem-se fagocitando pigmento biliar, exibiam hipertrofia e hiperplasia em graus de intensidade variável. Com certa freqüência as veias e os sinusóides centro-lobulares encontravam-se dilatados ou algo congestionados, acompanhando em intensidade a dissociação trabecular. Focos de infiltrado inflamatório mononuclear são geralmente verificados não correspondendo contudo à quantidade apreciáveis. Em muitos casos encontramos o espaço de Disse dilatado contendo material amorfo eosinófilo de permeio a raros elementos inflamatórios constituídos de mono ou de polimorfonucleares. A periferia do lóbulo hepático encontra-se geralmente preservada contrastando com o centro do lóbulo o que pode ser verificado tanto com a visão panorâmica do prepara-

do histológico como através do estudo do arcabouço reticular hepático como sobretudo pela ausência de alterações na rêde canalicular biliar em nítido contraste com o centro do lóbulo. Por sua vez os espaços porta participam pouco do processo, notando-se discreto inflitrado mononuclear, com raros neutrófilos e ausência de proliferação de dúctulos perilobulares ou de ductos portais, não se encontrando colestase a êste nível (Fig. 1, 2, 3,4).

Comparando-se êstes aspectos histológicos com o material contrôle, devemos considerar a possibilidade de sua semelhança com quadros de hepatite a virus em fase colestática, com as hepatites tóxicas ou por drogas ou sobretudo com as colestases intra-hepáticas em que há "estagnação biliar centro-lobular". Não consideramos difícil a diferenciação com os aspectos da hepatite biliar com colangite por obstrução extra-hepática devido a intensidade colestática e a participação portal e da periferia do lóbulo neste processo. Nos casos de hepatite a vírus em fase colestática, podemos fazer sua diferenciação pela verificação aqui de um componente mais difuso com menor predomínio centro-lobular e alterações parenquimatosas mais acentuadas. Nas colestases intra-hepáticas das hepati- tes colangioliticas por drogas, torna-se mais difícil a diferenciação com o quadro histológico da hepatite colestática centro-1obular das leptospiroses desde que a estagnação biliar centro-lobular nas primeiras é um fenômeno importante. Consideramos como fator importante de diferenciação entre as mesmas, a preponderância centrolobular da dissociação das traves hepáticas e da dilatação venosinusoidal, bem como o componente parenquimatoso mais característico no aspecto das leptospiroses do que naqueles das hepatites por drogas.

A complexidade e a interpretação fisiopatológica da colestase fazem com que freqüentemente múltiplos elementos sejam evocados para sua patogênese assim como em sua ctiologia (30).

Evidentemente que nos casos de maior dificuldade devemos lançar mão do quadro clínico-laboratorial confrontando-o com os achados histológicos, o que na nossa experiência tem funcionado com perfeito sucesso.

Do ponto de vista histopatológico os danos hepáticos ocasionados pelas leptospiroses podem ser englobados como quadro lesional de colestase intra-hepática com alteraçōes canaliculares e componente parenquimatoso de localização caracterìsticameace centro-lobular, o que nos permite denominá-lo de hepatite colestática centrolobular.

Louvados na comparação entre os aspectos histológicos e o quadro clínico-laboraioral. varif:a ado, de um lado que o componente obstrutivo parcebido pelas provas de função hepática e do outro lado as alterações colestáticas-canaliculares do quadro histológico, somos de opinião de que o componente obstrutivo intra-hepático é sem dúvida alguma um elemento importante na gênese da ictericia no curso das leptospiroses. Existe também um componente parenquimatoso histològicamente comprovado e também já verificado através estudos de microscopia eletrônica (10, 11, 12) e tais alterações descritas no pólo sinusoidal do hepatócito e ao nivel da célula hepática no que concerne a conjugação e a captatẹ da bilirrubina são elementos que também contribuem para a icterícia. Estes mesmos autores $(10,11,12)$ descrevem alterações importantes nas mi- 


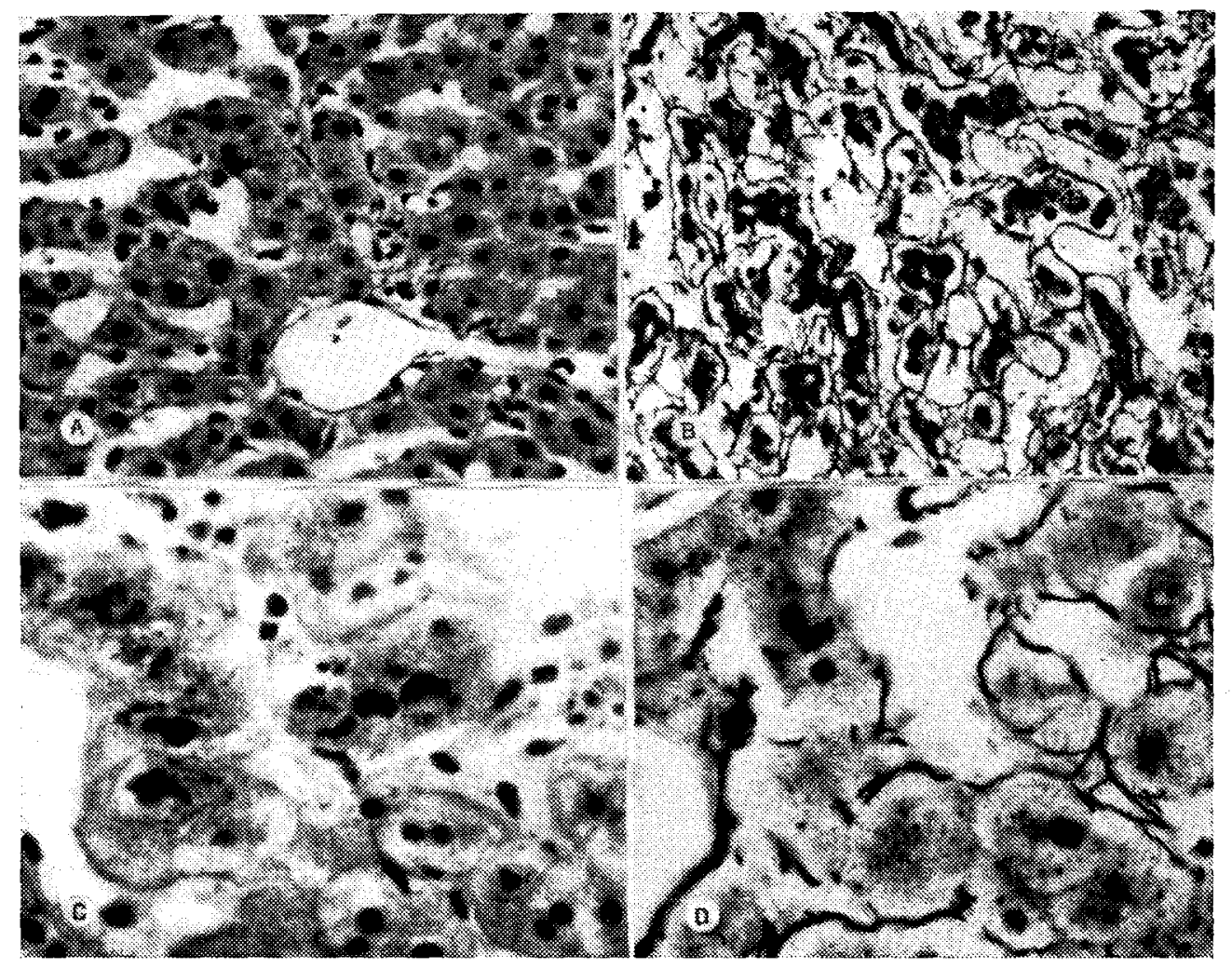

FIGURA 2 - Aspectos da dilatacão sinusoidal e da dissociação trabecular. Notar em C colestase intra-hepatocitária e trombos biliares. (A e C - H.E. médio e grande aumentos. Em B e D médio e grande aumentos - Reticulina de Gomori.) 
crovilosidades do polo excretor da célula hepática, assim considerando que a excreção biliar prejudicada pelo sistema canalicular alterado e levando em conta todos êstes elementos, poderíamos justificar:

1. Aumento da bilirrubina indireta por deficiência de captação ao nível do polo sinusoidal assim como defeito de conjugação ao nível da intimidade do hepatócito.

2. Aumento da bilirrubina direta, da fosfatase alcalina e do colesterol que traduziriam quadro obstrutivo laboratorial em conseqüência de lesões situadas ao nivel do polo excretor da célula hepática e por alterações do sistema biliar canalicular com colestase intra-hepática.

Tais fatos permitem-nos considerar como fator primordial na gênese da ictericia nas leptospiroses o componente obstrutivo intra-hepático aliado a alterações funcionais do hepatocito. Desde que a necrose hepática é insignificante, elevaçōes acentuadas das transaminases não seriam de se esperar. É provável que algum grau de hemólise também contribua para a gênese da ictericia, assim com alterações na função renal.

TABELA I

L E P T OS PIROSE

HEPATITE COLESTÁTICA CENTROLOBULAR

Relação entre Histcpatologia hepảtica e Provas funcionais

\begin{tabular}{|c|c|c|c|}
\hline $\begin{array}{l}\text { LESÕES DISCRETAS } \\
-13 \text { CASCS - }\end{array}$ & $\begin{array}{c}\text { LESÕES MODE- } \\
\text { RADAS } \\
-15 \text { CASOS - }\end{array}$ & $\begin{array}{l}\text { LESŌES ACEN- } \\
\text { TUADAS } \\
-11 \text { CASOS - }\end{array}$ & $\begin{array}{l}\text { PROVAS NA OCA- } \\
\text { SIÃO DA } \\
\text { BIÓPSIA }\end{array}$ \\
\hline $\begin{array}{c}2,0-0,5 \\
\text { Média }=1,3\end{array}$ & $\begin{array}{c}5,0-1,2 \\
\text { Média }=3,1\end{array}$ & $\begin{aligned} 30,0 & -5,0 \\
\text { Média } & =12,1\end{aligned}$ & $\begin{array}{l}\text { BILIRRUBINA } \\
\text { TOTAL }\end{array}$ \\
\hline $\begin{array}{l}25-10 \\
\text { Média }=15\end{array}$ & $\begin{array}{c}20-10 \\
\text { Média }=14\end{array}$ & $\begin{array}{l}22-12 \\
\text { Média }=14\end{array}$ & $\begin{array}{c}\text { FOSFATASE ALCA- } \\
\text { LINA } \mathbf{K} . \text { A. }\end{array}$ \\
\hline $\begin{array}{c}431-197 \\
\text { Média }=258\end{array}$ & $\begin{array}{c}344-173 \\
\text { Média }=291\end{array}$ & $\begin{array}{c}369-271 \\
\text { Média }=325\end{array}$ & COLESTEROL \\
\hline $\begin{array}{c}95-12 \\
\text { Média }=: 34\end{array}$ & $\begin{array}{c}76-26 \\
\text { Média }=43\end{array}$ & $\begin{array}{c}64-16 \\
\text { Média }=35\end{array}$ & T.G.O. \\
\hline $\begin{array}{c}220-26 \\
\text { Média }=52\end{array}$ & $\begin{array}{c}129=35 \\
\text { Média }=65\end{array}$ & $\begin{array}{c}115-35 \\
\text { Média }=65\end{array}$ & T. G. P. \\
\hline $\begin{array}{c}63-50 \\
\text { Média }=61\end{array}$ & $\begin{array}{c}72-40 \\
\text { Média }=57\end{array}$ & $\begin{array}{c}100-30 \\
\text { Média }=67\end{array}$ & $\begin{array}{l}\text { ATIVIDADE } \\
\text { PROTROMBINICA }\end{array}$ \\
\hline $\begin{array}{c}3,8-1,5 \\
\text { Média }=2,8\end{array}$ & $\begin{array}{c}3,4-1,9 \\
\text { Média }=3,0\end{array}$ & $\begin{array}{c}5,1-0,9 \\
\text { Média }=2,5\end{array}$ & ALBUMINA \\
\hline $\begin{array}{c}2,7-1,8 \\
\text { Média }=2,0\end{array}$ & $\begin{array}{c}3,0-1,1 \\
\text { Média }=2,0\end{array}$ & $\begin{array}{c}2,5-1,1 \\
\text { Média }=1,9\end{array}$ & GLGBULINA \\
\hline$=$ & + & ++ & $\begin{array}{l}\text { PROVAS DE } \\
\text { FLOCULAÇĀO E } \\
\text { TURVAÇÃO }\end{array}$ \\
\hline
\end{tabular}




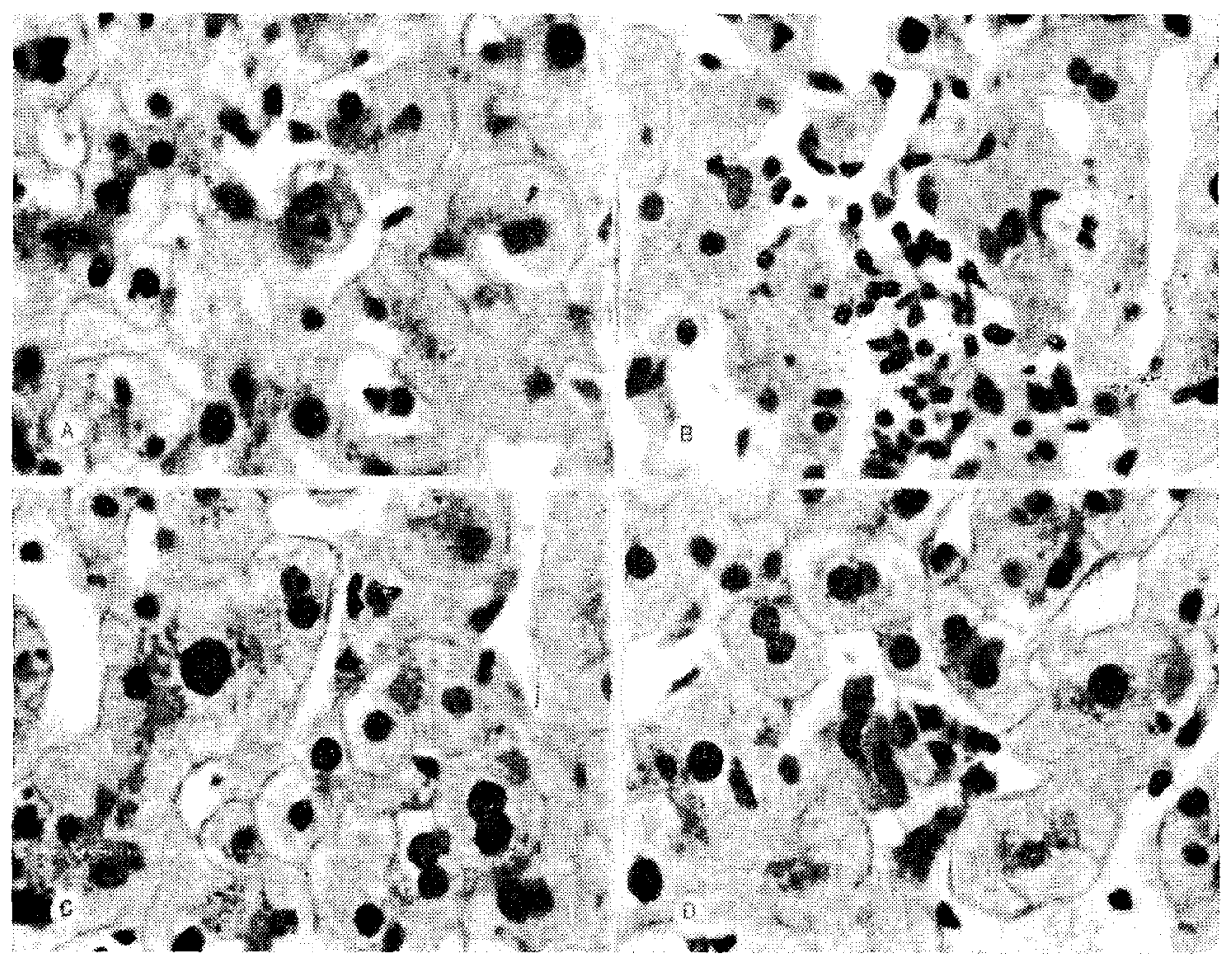

FIGURA 3 - A - Degeneraça hidrópica e hialina de hepatócitos, B - Infiltrado inflamatório focal. C - Regeneraçăo hepatoceluarar. D - Prolife ação Kupiferiana com hipertrofia e fagocitose de pigmento biliar em células $d$ : Kupfer. (H.E. grande aumento.) 
TABELA II

\section{HEPATITE COLESTÁTICA CENTRO-LOBULAR,}

Análise histopatológica de 42 casos de leptospirose

\begin{tabular}{|c|c|c|c|c|}
\hline TIPOS DE LESÕES & \begin{tabular}{c}
\multicolumn{1}{c}{ SEM } \\
LESOOES \\
4 casos* \\
$9,5 \%$
\end{tabular} & $\begin{array}{c}\text { LEHSÓES } \\
\text { DISCRETAS } \\
10 \text { casos } \\
23 \%\end{array}$ & $\begin{array}{c}\text { LESÕES } \\
\text { MODERADAS } \\
15 \text { casos } \\
35 \%\end{array}$ & \begin{tabular}{|} 
LESÕES \\
ACENTUADAS \\
12 casos \\
$32,5 \%$
\end{tabular} \\
\hline & & $(\cdots \cdots$ & $\cdots$ & \\
\hline ase & 0 & $100 \%$ & $100 \%$ & $100 \%$ \\
\hline zação centro-lobular & 0 & $100 \%$ & $100 \%$ & $100 \%$ \\
\hline iação trabecular & 0 & $100 \%$ & $100 \%$ & $100 \%$ \\
\hline eraçãc hepatocitária & 0 & $100 \%$ & $100 \%$ & $100 \%$ \\
\hline eração hepatocitária & 0 & $64 \%$ & $73 \%$ & $100 \%$ \\
\hline acãão kupfferiana & 0 & $50 \%$ & $68 \%$ & $100 \%$ \\
\hline ção veno-sinusoidal & 0 & $67 \%$ & $73 \%$ & $80 \%$ \\
\hline $\begin{array}{l}\text { ado inflamatório } \\
\text { ortal }\end{array}$ & 0 & $60 \%$ & $72 \%$ & $80 \%$ \\
\hline ado inflamatório focal & 0 & $50 \%$ & $67 \%$ & $78 \%$ \\
\hline
\end{tabular}

* Formas anictéricas da doença.

Na tabela I consideraçōes em relação entre aspectos histopatológicos e provas funcionais são apresentadas assim como uma classificação das lesões.

Na tabela II uma classificação geral das lesões histológicas é realizada onde podemos notar que lesões estão ausentes nas formas anictéricas e que nas formas ditas discretas, moderadas e acentuadas a localização centro-lobular da lesão, a colestase, dissociação trabecular e a degeneração hepatocitária estiveram presentes em $100 \%$ dos casos.

\section{DISCUSSĀO}

A patogenia das leptospiroses continua sendo um campo aberto aos pesquisadores desde que grande parte das manifestações clínicas não encontram uma correlação nas características biológicas das leptospiras assim como os aspectos anatômicos de amostras de biopsia ou necropsia. Os mecanismos dos danos tissulares nestas infec- ções permanecem ainda quase que totalmente desconhecidos $(3,4,5,10,11,12,22$, 35,37 ) .

Imamura (22) relatou a presença de uma tcxina capaz de produzir necrose cutânea.

Stavitsky (38) em estudos sôbre a patogenia das leptospiroses não confirmou a presença de toxinas assim como Arean e cols., que também não foram capazes de demonstrar a elaboração por parte das leptospiras de endo ou exo toxinas. Encontraram os últimos autores evidências de que extratos de órgão de animais sacrificados durante a fase febril possuem muitas das propriedades das endotoxinas (6).

Existe também evidência de que certas cepas de leptospiras elaboram substâncias hemoliticas em culturas (35).

Estudos histoquímicos têm sido realizados com a finalidade de se conhecer a natureza dos danos celulares nas leptospiroses. 


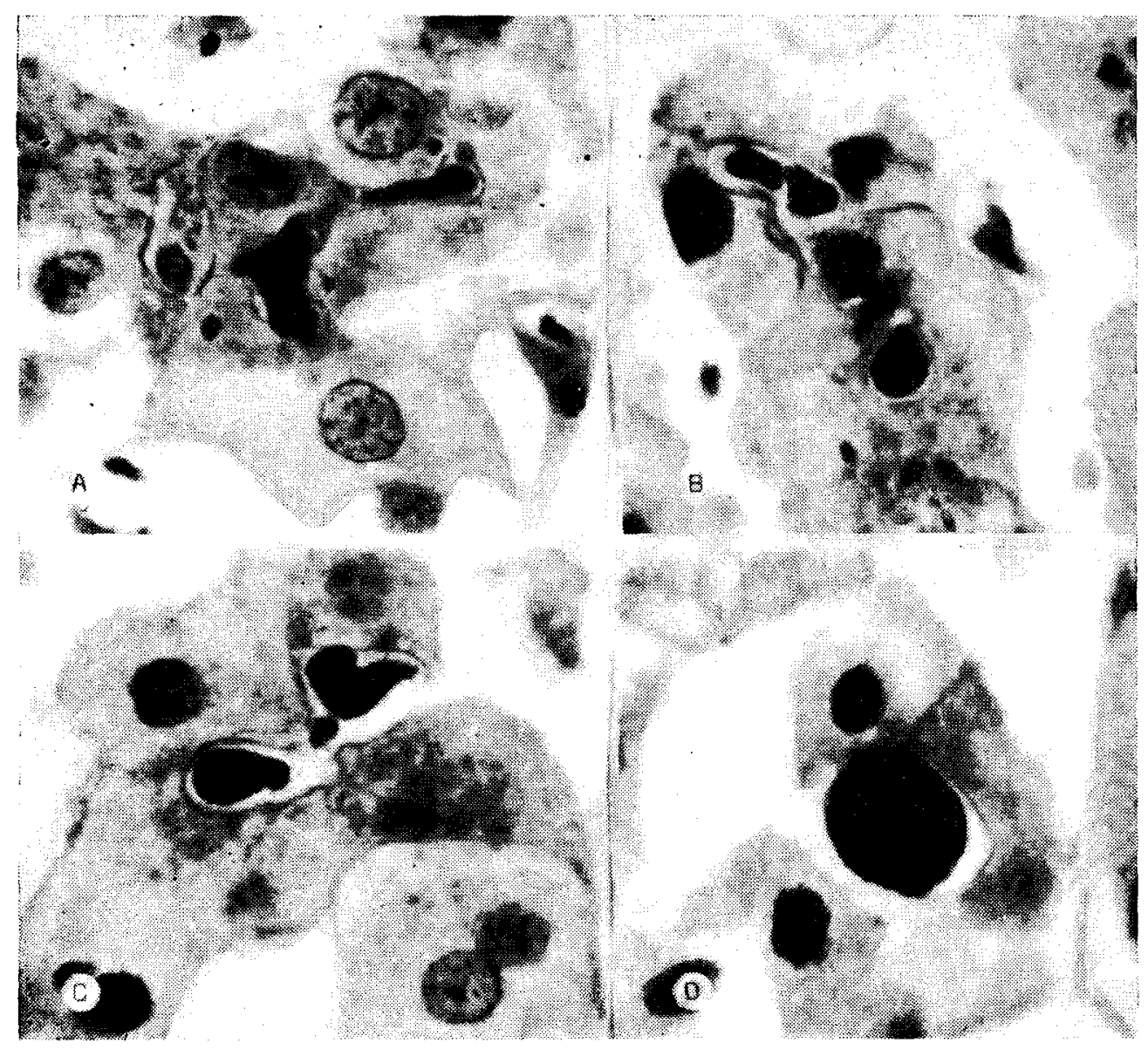

FịcüA 4 - Detalhes da colestase centrolobular, evidenciando distorção canalicular ,com formaçắ de divertículos e de trombos de volumes variávels (Técnica de Luna e lshack para canalículos biliares. Imersãc.) 
Arean e Henry encontraram uma pronunciada diminuição em sistemas enzimáticcs, particularmente das desidrogenases (3) nos rins e fígado, sendo que neste último sòmente as desidrogenases succinica e isocítrica estavam marcadamente diminuídas.

Brito fêz determinações bioquímicas em rins biopsiados que evidenciaram uma diminuição da atividade enzimática, particularmente das fosfatases ácidas e alcalina e da succinodesidrogenase $(11,12)$. Se a toxina ou toxinas agem diretamente sôbre as células ou se seu mecanismo de ação é primàriamente sôbre os capilares com diminuição de oxigênio para os elementos celulares, são possibilidades bastante válidas no entanto ainda carecem de melhores demonstrações (12).

Brito tem assinalado não sòmente lesões de membrana celular mas também do citcplasma, onde se podem notar vacúolos autofágicos que indicam comprometimento celular. Tem demonstrado além disso alterações capilares no decurso da patologia das leptospiroses (12).

Sefer e Comby (14) isolaram a partir de células de leptospiras uma fração glicido-lipido-polipeptídica tendo as características de uma endotoxina levantando assim a possibilidade de uma ação tóxica responsável em parte pelas lesões observadas. O caráter difuso das alterações encontradas na patologia poderiam ter uma explicação como conseqüência dos distúrbios hemodinâmiccs e hemorrágicos.

As hemorragias podem ser o resultado do aumento da permeabilidade capilar induzidas por alterações na parede vascular que podem ser nitidamente visualizadas através microscopia eletrônica em patologia experimental $(10,11)$.

Alterações da coagulação intravascular foram também discutidas como mecanismo patcgenético da doença $(4,5)$.

Parece-nos que uma ação direta tóxica explicaria bem o quadro clínico assim como os achados de patologia; no entanto os elementos envolvidos na fisiopatologia da doença devem ainda ser melhor caracterizados do ponto de vista experimental.

Klatskin (23) sugeriu que existe no parênquima hepático, apesar de aparentemente intacto, um distúrbio na excreção da bilirrubina.
Thiel considerando a pequena degeneração hepatocelular em ccntraste às vêzes com a intensidade da icterícia e aumento da bilirrubina indireta em certos casos, sugere a hemólise como causa principal da icterícia e dá ênfase ao que afirma chamando a atenção de que raramente o paciente falece de insuficiência hepática em virtude da falta de lesões degenerativas ao nível do fígado (40).

Ramos-Morales e cols. (34) em análise de 235 cascs chegaram à conclusão de que a hemólise não é um fator importante no mecanismo da icterícia pois não constataram relação entre causa e efeito, assim é que severa hiperbilirrubinemia surgiu sem alterações na série vermelha. Demonstraram também neste estudo evidência de disfunção hepática nos pacientes ictéricos e anictéricos, fatos assinalados no material por nós apresentado. Valorizaram ainda a obstrução biliar intra-hepática e discutiram o papel da insuficiência renal na manutenção da hiperbilirrubinemia. Quanto à hemólise como causa de icterícia achamos que é um elemento secundário (32, $34,36)$.

Chinn e cols. (13), Austoni e Treu (8), Arean (5), Edwards (19), Machado da Silva (27) e Pereira da Silva e cols., (29) advogam a origem hepática da icterícia.

Ashe, baseado em evidências histológicas, acredita numa hepatite como causa fundamental e assinala como fatôres secundários a hemólise e a obstrução biliar intra-hepática (7) .

Austroni e Treu (8) em estudo clínico, hematológico, bioquímico e histopatológico deféndem o dano celular hepático como mecanismos mais importante da icterícia; secundàriamente estariam os fatôres hemolítico e colestático.

Estudos de microscopia eletrônica realizados por Brito $(11,12)$ demonstram alterações nas microvilosidades dos canaliculos biliares. Além disso, as células hepáticas mostravam alterações mitocondriais e depleção dos grânulos de glicogênio e de ribonucleina. Finaliza sugerindo que o metabolismo da bilirrubina está perturbado na captação (injúria do polo sinusoidal), conjugação (depleção dos grânulos de ribonucleina) e excreção (patologia mitocondrial e de dutos biliares) com a predominância da última fase. 
Alterações na microscopia eletrônica foram também assinaladas por Sandborn, Côté e Viallet (37).

Em resumo diríamos que cs principais fatôres responsáveis pela icterícia são deficit funcional da célula hepática, alterações importantes na excreção da bilirrubina, colestase intra-hepática e que a hemólise seria um fator secundário assim como a insuficiência renal.

A necrose hepática do ponto de vista funcional é sempre pouco expressiva encontrando correspondência com o quådro histológico de necrose hepática pouco apreciável.

Não há dúvida de que o deficit funcional por parte da célula hepática é marcante e é expresso por hipoalbuminemia às vêzes acentuada e queda da atividade protrombínica sem resposta à administração da vitamina $\mathbf{K} 1$, embora trabalhos prévios tenham demonstrado o inverso (34).

Apesar dêstes pacientes exibirem icterícia apreciável em muitas ocasiōes e de exibirem alterações funcionais bioquimicas, salientamos que não falecem de insuficiência hepática aguda como ccorre nas hepatites infecciosas ou tóxicas a não ser que tenham uma hepatopatia prévia. Tal afirmativa baseia-se no fato de que torpor ou coma vigil são achados relativamente comuns nas formas severas de leptospirose, no entanto as características do coma hepático não são freqüentemente observadas. Até o presente momento pelo que observamos esta forma de hepatopatia regride sem sinais de sequelas ou de evolução para cronicidade.

Koppisch e Bond em material de necropsia de 13 casos descreveram a presença de numerosos hepatócitos binucleados, aumento das células de Kupffer, dissociação das trabéculas hepáticas, tumefação turva das células do parênquima, variação no tamanho dos núcleos e presença de bile nos canalículos. A necrose hepática em seu material não foi importante (24) .

Ichinose e cols. em estudo de 6 casos de evolução fatal notaram que a estrutura lobular era bem preservada, ocasionais trombos biliares eram vistos nos canalículos localizados nas áreas centro-lobulares e pigmento biliar estava presente no citoplasma das células hepáticas nas mesmas áreas. Células binucleadas eram freqüentes e oca- sionalmente multinucleadas sugerindo regeneração hepática recente. Mitose foi presente e abundante em 1 caso, dissociação das células hepáticas estêve presente em 2 casos. Vários graus de alteração edematosa nos espaços porta e nos espaços peri-sinusoidais de Disse foram observados. Colangite de intensidade média era aparente, principalmente ao redor dos lóbulos demonstrando pigmento biliar. Alterações degenerativas em células hepáticas nas áreas centrais assim como isoladas em outras partes do lóbulo foram mínimas. Leptospiras foram achadas em todos os casos em cortes coraảos pela prata; o autor não considerou as alterações hepáticas específicas (21)

Arean, em estudo de 33 casos fatais, demonstrou que a alteração mais característica foi a desorganização das células hepáticas. As células do parênquima variaram em tamanho e forma; algumas eram encoIhidas com o citoplasma profundamente eosinofílico, o contôrno da célula irregular e picnose. Outras eram aumentadas e poliédricas com abudante grânulos basófilos. Grande númerc de células bi, tri e multinucleadas foram assinaladas. Figuras de mitose eram exuberantes e pigmento biliar moderado foi notado no citoplasma das céiulas hepáticas ao redor da zona central em 6 casos. Hiperplasia das células de Kupffer e eritrofagocitose foram descritas. Os sinusóides eram congestos e hemorragias difusas ou focais foram vistas. Assinalou ainda alterações ao nivel dos espaços de Disse assim como presença de estruturas acidófilas, irregulares, lembrando os corpúsculos de Councilman. Tampão de bile entupindo os canalículos oue continham cilindros biliares foi detectado em 5 pacientes mais marcadamente na periferia dos lóbulcs.

Em 4 pacientes as lesões consistiram de miríades de focos necróticos distribuídos ao acaso. Havia colapso e fragmentação das fibras de reticulina. Interessante é que em 5 pacientes não foram constatadas alterações histológicas a não ser edema intersticial, congestão e' hemorragias focais. É de se ressaltar que todos os casos analisados por Arean estavam ictériccs na época da necropsia (5).

Estranhamos a ausência de achados histopatológicos mais convincentes desde que 
em experiência de autópsia e em achados de biopsias algumas realizadas em fase bem tardia da doença, temos enccntrado em muitos casos dados compatíveis com hepatite colestática centro-lobular $(32,33,34$, 36).

Machado da Silva em 3 biopsias hepáticas realizadas em períodos evolutivos diferentes, encontrou cclestase intra-hepática em 1, células hepáticas com pigmento biliar no citoplasma em 2, preservação da estrutura lobular em todos e espaços-porta ncrmais. Não foram visualizados trombos biliares (27).

Alves Meira (2) em análise histológica de estudos experimentais em cães demonstrou que as alterações hepáticas são caracterizadas por destrabeculação dos hepatócitos que muitas vêzes são multinucleados e ocasionalmente ccm figuras de mitose. Nos cães estudados observou ainda intensa hiperplasia reticulo-endotelial e discreto infiltrado Inflamatório crônico no espaço portal. Esteatose das células hepáticas freqüentemente multinucleadas foi observada ncs casos menos severos.

A nossa experiência como demonstrada no trabalho entra em desacôrdo com o que ter: sido descrito na literatura por Brito, Dotti e Ostertag $(12,15,28)$, desde que temos encontrado dissociação trabecular, colestase predominantemente centro-lobular, trombos biliares no interior dos canalículos, estase biliar hepatocitária, alterações hepatocelulares degenerativas associadas a regeneração. Aquêles autores ccmentam que estas alterações estão ausentes em biopsias hepáticas a não ser em fases terminais ou durante o período de maior agudização da doença.

Ostertag descreveu alterações hepáticas em biopsias caracterizadas pela presença de exsudato sero-sanguinolento nos espaços de Disse, proliferação dos endotélios capilares, hipertrofia e hiperplasia das células de Kupffer (28).

Comby focalizando dados de histopatologia cbtidos de autopsia de 10 pacientes encontrou arquitetura trabecular deslocada em 2 nos quais a evolução foi mais rápida. Os hepatócitos estão isolados, arredondados, com o citoplasma retraído, acidófilc ou granuloso e os núcleos quase em picnose. Nestes 2 casos não foram notadas mi- toses ou sobrecarga biliar. Na maicria das vêzes a estrutura é conservada mas constata-se uma importante dilatação dos sistemas porta e supra-hepático. Os sinusóides estão dilatados e congestionados mais nitidamente nas regiōes centro-lobulares. Mitoses freqüentes foram descritas em 3 casas. A sobrecarga biliar é usual e a presença de pequenos trombos uma constante. As células de Kupffer quase sempre mobilizadas e os infiltrados com células mononuclares sempre discretos sem aumento do colágeno (14).

Guedes (29) baseado em 5 casos de necropsia refere ser a destrabeculização hepática o achado mais freqüente, encontrando-se os elementos celulares nobres desordenádos dentro do lóbulo. Encontrou também com freqüência atrofia isolada dos hepatócitos mais evidente em tôrno da veia centro-lobular. Outros achados assinalados são espaços de Disse ccm líquido de edema, hipertrofia das células de Kupffer contendo em alguns casos pigmento pardo-amarelado em seu citoplasma e espaços-porta exibindo infiltrado inflamatório predominantemente linfocitário.

Duarte (32), em estudo de 5 casos de biopsia e 2 de necropsia, descreveu alterações significativas e caracterìsticamente situadas ao nível do centro dos lóbulos e mais intensamente em tôrno das veias centro-lobulares, com dissociação trabecular intensa, dilatação sinusoidal, alteraçôes hepatocelulares degenerativas associadas a regeneração hepatccitária e Kupfferiana. Como dados ainda importantes encontrou trombos biliares no interior dos canalículos, estase biliar hepatocitária, colestase predominantemente centro-lobular, dencminando ao quadro assim composto de hepatite colestatica centro-lobular $(32,36)$

CONSIDERAÇŌES FINAIS E CONCLUSÓES

1. O quadro histológico hepático das leptcspiroses é o de uma hepatite colestática centro-lobular.

2. Existem alterações histológicas características que correlacionadas com a clínica e o laboratório permitem firmar o diagnóstico mesmo em presença de sôro-aglutinações negativas 
3. A biopsia hepática é importante e fornece elementos capazes de diferençar o aspecto histológico com o de outras hepatopatias que levam ao aparecimento de colestase intra-hepática.

4. O estudo correlativo clínico-laboratorial-histopatológico permite a explicação da icterícia nas leptospiroses, considerando as alterações do polo excretor hepatocitário ao lado das modificações da rêde biliar canalicular propiciadoras de colestase intra-hepática como as alterações mais importantes para a gênese da icterícia.

5. Alteraçōes funcionais importantes são também evidenciađas e concorrem com destaque para a crigem da icterícia e estas alterações estariam perturbadas principalmente na fase da captação e da conjugação da bilirrubina.

6. Ao que parece a hemólise é um fator secundário não ocupando em nosso material lugar de destaque.

7. As lesões histológicas hepáticas podem perdurar por mais de 30 dias após o início dos sintcmas e serem ainda bastante tipicas da doença.
8. Nas formas anictéricas ocorrem transtornos funcionais sem alterações histopatológicas expressivas.

9. As lesões histológicas mais importantes são a localização centro-lobular da lesão, a dissociação das trabéculas, a colestase e a degeneração hepatocitária.

10. A doença hepática não evolue para alterações crônicas.

11. Raramente os pacientes falecem de verdadeiro coma hepático.

12. A presença de leptospiras em biopsias ou mesmo em autopsias não foi detectada em nenhuma ocasião provàvelmente em conseqüência do uso de antibióticos no tratamento da infecção.

13. A necrose hepática do ponto do vista funcional e histopatológico não é $\mathrm{ex}$ pressiva.

14. A biopsia hepática em nossa experiência é um procedimento inócuo des̃de que realizada com cuidados especiais; em nenhuma ocasião complicações surgiram.

The authors call attention to the epidemic-endemical character of Leptospirosis occurring in the city-state of Guanabara (Rio de Janeiro - Brazil) and its surroundings.

They lay down data concerning both the severity of the infection and the poor knowledge of the anicteric form of the disease.

They further emphasize the digestive manifestations of Leptospirosis as well as the importance of inserting this condition in the differential diagnosis of the "surgical-abdomen", chiefly when jaundice is also present.

They regard such findings as anuric acute renal failure, aigestive tract hemorrhages, convulsions and/or shock as valuable indications of a very poor prognosis.

Among the digestive manifestations of the disease, the authors have specially stressed hepatic involvement and of course, jaundice.

The presenting material is made up of 42 cases of Leptospirosis, which have been thouoh rouly studied both from o. functional and is histopathological standpoint. The material was obtained through biopsy-puncture except for 3 cases, which were autopsied.

The deepest jaundice was found about the 2 nd and 3 rd weeks in the course of the disease and the prevalente fraction of the hyperbilirubinemia was the "direct one".

Fairly high serum alkaline phosphatase and cholesterol, side by side with severe hyperbilirubinemia, occurring at the $2 n \bar{d}$ and 3 rd weeks in the contse of the disease gave clue to the presence of an important obstructive component, which proved to be the fact through the histopathological findings. In no instance have the transamimase levels exceeded 250 Karmen units. No important hepatic necrosis was found in any of the histopathological specimens examined.

Prothrombinic activity less than 60\% was found in 22 patients and those who were given vit. K1 shcwed no response whatsoever.

The chief protein electrophoretic changes found in 26 patients were as follows: hypoalbuminemia and high alpha-2 fraction in all of the $m$; beta-fraction over $0.90 \mathrm{~g} \%$ in 14 patients; gamafraction over $1.4 \mathrm{~g} \%$ in 15 patients.

Both the flocculation and turbidity tests showed fairly significant changes in 14 patients.

The chief pathological changes found were: predominance of centro-lobular lesions, trabecullar derangement, cholestasis, degenerative as well as regenerative changes of the main liver cells, and, hyperplasia of Kupffer cells. Such findings can be obtained in patients after a period of 30 days from the initial symptoms.

Finally, the authors analyse the pathogenical features of the disease as well as the physiopathology of hepatic lesions in the course of Leptospirosis. 


\section{BIBLIOGRAFIA}

1. ALSTON, J.M. and BROOM, J.C. Leptospircsis in man and animals, Edinburgh, $\mathbf{E}$. and $\mathbf{S}$. Livingstone, L.T.D. p. 376,1958 .

2. ALVES MEIRA, D. - Alteraçōes cardíacas na leptospirose experimental do cão. Estudo eletrocardiográfico, anatomopatológico e sua importância na interpretação da patogenia da doença. São Paulo, 1967. Tese.

3. AREAN, V.M. and HENRY, J.B. Studies on the pathogenesis of leptospirosis. IV. The behavior of transaminases and oxidative enzymes in experimental leptospirosis: a histochemical and biochemical assay. Am. J . Trop. Med. 13: 430, 1946.

4. AREAN, V.M. - Studies cn the pathogenesis of leptospirosis. II. A clinicopathologic evaluation of hepatic and renal function in experimental leptospiral infection. Lab. Invest. 11: 273, 1962 .

5. AREAN, V.M. - The pathologic anatomy and pathogenesis of fatal human leptospirosis (Weil's disease). Am. J. Path. 40: 393, 1962.

6. AREAN, V.M.; SARASIN, G. \& GREER, J.H. - The pathogenesis of leptcspirosis: toxin production by Le ptospira icterohaemorrhagiae. Amer. J. Vet. Res. 25: 727, 1964.

7. ASHE, W.F.; PRATT-THOMAS, H.R. and KUMPKE, C.W. - Weil's disease: a complete review of American literature and an abstract of world literature. 7 case reports. Medicine 20: 145, 1941.

8. AUSTONI, M.; TREU, L. -- L'ittero nella leptospirosi itttero emorragica. Sue caracteristiche e patogenese. Policlinico, Sez. med. 58: 358, 1951.

9. AUSTONI, M. - Le leptospircsi. Tourino, Edizione Minerva. Med. 1953.

10. BRITO, T.; FREYMỨLLER, E.; HOSHINO, S. \& PENNA, D.O. - Pathology of the kidney and liver in the experimental leptospirosis of the guinea-pig: a light and electron microscopy study. Virchow Arch. Path. Anat. 341: 64, 1966.

11. BRITO, T.; MARCONDES MACHADO, M.: MÓNTANS, S.O.; HOSHINO, S. \& FREYMÚLLER, E. - Liver biopsy in human leptospirosis: a light and electron microscopy study. Virchow Arch. Path. Anat. 342: 61, 1967.

12. BRITO, T. - On the pathogenesis of the hepatic and renal lesions in leptospirosis. Rev. Inst. Med. Trop. São Paulo, 10: 238, 1968.
13. CHINN, A.B.: ROTH. H.P. and MOR.E. R.D. - Hepatic function tests in Weil's disease. Am. J. Med. Sci. 222: 530,1951 .

14. COMBY, F.; GAUTHIER, R. et NAZIMOTT, $O$. - Nouvelle contribution a l'étude des leptospiroses a la reunion. II. Anatomopathologie et histopathologie de dix cas mortels. Bulletin de La Societé de Pathologie Exotique e de ses filiales. $T$. $62, n$, 1,92 , 101, 1969 .

15. DOTTI, F. \& SABBIONI, G. - Il quadro isto morfologico del fegato nelle leptospirose .benigna: studio bioptico com particolare riguardo alle forme anicteriche.' Arch. Pat. Clin. Med. $36: 81,1959$.

16. EDELWEISS G.L. - Leptcspiroses humanas. Contribuicão ao seu estudo. Pôrto Alegre. Globo, 1962 (Tese).

17. EDWARDS, G.A. and DOMM, B.M. - Human leptospirosis. Medicine 39: 117,1960

18. EDWARDS, G.A. and WEIR, T.F. Leptospiral jaundice simulating commong duct obstruction. Am . Surgeon 30: 619,1964 .

19. EDWARDS, G.A. and DOMM, B.M. Leptospirosis. Medical Times, August and September, vol. $94, n .^{\circ} 8$ and n. 9,1966 .

20. ELKIS, H. ; AMATO NETO, V. \& MEIRA, J.A. - Transaminase glutamico-oxalacética no sôro de pacientes com leptospirose. Rev. Inst. Med. Trop. São Paulo 4: 217, 1962

21. ICHINOSE, H.; ESTRADA, $H$. and ROTH, E.E. - Observations on Weil's disease with a report of 6 recent deaths in Louisiana. Bull. Tulane Med. Fac. 22: 81, 1963

22. IMAMURA, S. ; KURIBABYASHI, $\mathbf{K}$. and KAMETA, M. - Studies on toxins of pathogenic leptcspira. Japan $J$. Microb. 1: 43, 1957.

23. KLATSKIN, G. - Leptospirosis. Veterans Admin. Technical Bull. T.B. 10-106, 1955.

24. KOPPISCH, E. and BOND, W.M. The morbid anatomy of human leptospirosis: a report of 13 fatal cases. Symposium on the leptospirosis. Medical Science Publication no 1 , Washington, D.E.U.S. Government Printing Office, 1953.

25. LUNA, L.G.; ISHAK, K.G. - A new stain for bile canaliculi. Am. J. of Medical Technclogy. 33: 1, 1967. 
26. MC CRUMB, F. R., JR.; STOCKARD, J.L. ; RCBINSON, C.R. ; TURNER, L.H.; LEVIS, D.G.; MAISEY, C.W.; KELLEHER, M.F.; GLEISHER, C. A AND SMADEL, J.E. - Leptospirosis in Malaya. Sporadic cases among military and civilian personnel. Am. J . Trop. Med. and Hyg. 6: 238, 1957.

27. MACHADO DA SILVA, R. - Estudo clínico e laboratorial da leptospirose icterohemorrhagiae (Doença de Weil). Bahia, 1966 (Tese).

28. OSTERTAG, H. - Leptospirosis icterohaemorrhagica in Bulgarien. $Z$. Hyg. Infektionskr. 131: 482, 1950.

29. PEREIRA DA SILVA, J.J.; PAIVA, L. M.; SOUZA NETTO, B.A.; GUEDES E SILVA, J.B.; COURA, J.R. - Estudo preliminar das leptcspiroses no Estado do Rio de Janeiro. Rev. Soc. Bras. Med. Trop., 2: 317, 1968.

30. POPPER, H. - Pathophysiology of cholestasis. Human Pathology. A clinicopathologic Quarterly, 1: 1, 1970.

31. RAMOS-MORALES, F.; DIAZ RIVERA, R.S.; CINTRON-RIVERA, A.A.; RULLAN, J.A.; BENENSON, A.S. and ACCSTA-MATIENZO, J _ The pathogenesis of leptospiral jaundice. Ann. Int. Med. 51: 861, 1959.

32. RIOS GONÇALVES, A.J.; SANTINO FILHO, F.; DUAR;E, F. - Doença de Weil. Aspectcs epidemiológicos, clínicos, laboratoriais e anátomo-patológicos de 14 casos. Bol. Cent. Est. Hosp. Serv. Est. 19: 147, 1967.
33. RIOS GONCGALVES, A.J.; OLIVEIRA, S.M.R. - Doença de Weil simulando obstrução do colédoco. Bol. Cent. Est. Hosp. Serv. Est. 19: 127, 1967.

34. RIOS GONÇALVES, A.J.: SANTINO FILHO, F.; QUAGLIATO JR., R .; SUZUKI, L.E. - Formas graves do sindrome de Weil. Rev. Soc. Bras. Med. Trop. 3: 95, 1969 .

35. RUSSEL, C.M. - A "hemolysin" associated with leptospirae. J. Immunol. 77: 405, 1956.

36. S. JUAN, F .; DUARTE, F.; TREIGER, M. \& RIOS GONCCALVES, A.J. - ASpectos histológicos e funcionais do fígado na leptospirose ictero-hemorrágica. O Hospital 74: 95, 1968.

37. SANDBORN, E.B.; CôTe, M.G. and VIALLET, A. - Electron microsccpy of a human liver in Weil's disease (leptospirosis icterohaemorrhagica). The J. Path. Bact. 92: 369, 1966.

38. STAVITSKY, A.B. - Studies on the pathogenesis of leptospirosis. J. Infect. Dis. $76 ; 179,1945$.

39. TARTARI, J A .; WAJCHENBERG, B. VERONESI, R.; BIEHMER, O.; MEIRA, J.A.; CINTRA, A.B.U. - Pancreatite aguda na leptospirose icterohemorrágica. Rev. Med. e Cir. São Paulo 13: 37, 1953.

40. THIEL, P.H. van - The leptospirosis. Leiden, Universitaire, 231, 1948. 